\title{
DETERMINANTES DO TRABALHO INFANTIL NO BRASIL URBANO: UMA ANÁLISE POR DADOS EM PAINEL 2001-2009
}

\author{
Hilton Martins de Brito Ramalho* \\ Shirley Pereira de Mesquita ${ }^{\dagger}$
}

\begin{abstract}
Resumo
O artigo investiga os determinantes do trabalho infantil no Brasil urbano considerando as diferenças estaduais de renda e de estruturas dos mercados de trabalho. Para tanto, foram estimados modelos com controle para heterogeneidade não observada a partir de um painel de dados das PNADs de 2001 a 2009. Os resultados sugerem que o trabalho infantil está sujeito a persistências temporal e intergeracional, por um lado, e, por outro, que sua intensidade é agravada pela condição de pobreza e pelo grau de informalidade dos mercados regionais nos estados brasileiros.
\end{abstract}

Palavras-chave: Trabalho infantil; Brasil urbano; Persistência Intergeracional.

\begin{abstract}
The main goal of this paper is to investigate the determinants of child labor in urban Brazil taking into account the differences in state's income and structures of labor markets. In this intend, we estimated a set of models to account for unobserved heterogeneity using a panel of data provided by PNADs of 2001 to 2009. The findings suggest that the level of income per capita and the informality of regional markets play an important role in the intensity of child labor in the Brazilian states. Moreover, we also find temporal and intergenerational persistence of child labor in Brazil.
\end{abstract}

Keywords: Child labor; Urban Brazil; Intergenerational Persistence. JEL classification: C23, J22, J62

\footnotetext{
* Professor do Departamento de Economia — UFPB. E-mail: hiltonmbr@gmail.com

† Professora do Departamento de Economia — UFPB. E-mail: shirley_mesquita@yahoo.com.br
} 


\section{Introdução}

O trabalho infantil é um problema social de grande relevância no Brasil e no mundo. ${ }^{1}$ Na atualidade, principalmente devido à criação e expansão de agências multilaterais dedicadas à defesa dos direitos da criança e do adolescente, esse problema tem sido discutido no âmbito do Estado e da sociedade, com foco na elaboração de políticas públicas que venham combatê-lo.

As estatísticas sobre o trabalho infantil no Brasil demonstram considerável redução ao longo das últimas décadas. Em 1993, por exemplo, 20\% das crianças entre 10 e 14 anos de idade exerciam algum tipo de trabalho, conforme os dados da Pesquisa Nacional por Amostra de Domicílios (PNAD). Já em 2009, nessa mesma faixa etária, esse percentual sofreu uma forte diminuição, passando para $7,3 \%$ do total. ${ }^{2}$ Por outro lado, entre 1993 e 2009 , o percentual de crianças que frequentavam a escola, na faixa em destaque, passou de $88,3 \%$ para $97,7 \%$. Essa evolução positiva pode estar relacionada a diversos fatores que têm afetado o cenário político e econômico do Brasil desde a década de 90, com destaque para os programas sociais do Governo voltados ao combate do trabalho infantil no Brasil, de forma direta, a exemplo do Programa de Erradicação do Trabalho Infantil (PETI), implementado em âmbito nacional no ano de 2001, e indireta, a partir do Programa Bolsa Família, criado em 2003. ${ }^{3}$ Apesar dos avanços no combate ao trabalho infantil e dos atuais indicadores de universalização do ensino fundamental, o ingresso precoce no mercado de trabalho ainda pode comprometer o progresso econômico de muitos indivíduos e/ou famílias.

Por outro lado, cabe ainda ressaltar que a trajetória de declínio do trabalho infantil no Brasil tem se mostrado mais acentuada nas áreas rurais. Entre os anos de 2001 e 2009, os dados das PNADs apontam uma queda na taxa de crianças trabalhadoras de 13,2 p.p. na zona rural, enquanto na urbana esse declínio foi de 1,9 p.p. ${ }^{4}$ O declínio mais rápido, registrado no meio rural, possivelmente se relaciona a fatores culturais e aos baixos incentivos econômicos ao trabalho infantil. Na zona urbana, ao contrário, o trabalho infantil parece funcionar como estratégia de sobrevivência para famílias de baixa renda, ao permitir maiores oportunidades de trabalho e de remuneração. Desse modo, a maior dinâmica econômica das áreas urbanas parece elevar o custo de oportunidade de manter as crianças exclusivamente na escola (Duryea \& ArendsKuenning 2003).

A literatura empírica registra uma série de estudos acerca do tema em destaque. As evidências mais frequentes sugerem que o trabalho infantil é um fenômeno típico em famílias com baixo nível de renda. De forma geral, o direcionamento das crianças ao mercado de trabalho trata-se de uma estratégia de

\footnotetext{
${ }^{1}$ De acordo com a Organização Internacional do Trabalho (OIT), o trabalho infantil é definido como aquele realizado por "crianças e adolescentes", que estão abaixo da idade mínima para a entrada no mercado de trabalho, segundo a legislação em vigor no país. No caso do Brasil, a idade mínima para entrada no mercado de trabalho é de 16 anos, salvo na condição de aprendiz entre 14 e 16 anos (Ferreira Batista 2006).

${ }^{2}$ Ainda assim, esse último percentual corresponde a 1,2 milhões de crianças.

${ }^{3}$ Esse último programa tem como uma de suas contrapartidas a frequência das crianças a pelo menos $85 \%$ das aulas.

${ }^{4}$ Em termos de distribuição regional, os dados da PNAD 2009, por exemplo, apontam que a maior taxa de crianças trabalhadoras no Brasil está na região Nordeste $(14 \%)$, seguida pela região Sul $(10,9 \%)$ e Norte $(9,3 \%)$, e os menores percentuais, nas regiões Sudeste $(6 \%)$ e Centro-Oeste $(7,2 \%)$.
} 
sobrevivência dos pais, na qual é feita a opção pela elevação da renda corrente em troca do investimento em educação e da expectativa de renda futura (Basu 2000, Kassouf 2002, Ray 2002, Basu \& Tzannatos 2003). Além disso, fatores como estrutura/atratividade do mercado de trabalho e o nível tecnológico do sistema produtivo também são reportados como potenciais determinantes do trabalho infantil (Ferreira Batista \& Cacciamali 2007, Duryea \& ArendsKuenning 2003, Neves \& Menezes 2010). No Brasil, as explorações empíricas sobre a influência dos últimos fatores foram baseadas em regressões com variáveis agregadas para o mercado de trabalho cuja unidade de análise era a criança. Tal estratégia, possivelmente, prejudicou a inferência estatística ao violar o pressuposto de distribuição idêntica e independente das crianças na amostra, fragilizando, por conseguinte, alguns achados.

Outro conjunto de evidências bem documentadas na literatura favorece um possível impacto positivo de programas governamentais de distribuição de renda sobre a frequência escolar no Brasil (Cardoso \& Portela Souza 2004, Duarte \& Silveira Neto 2008, Glewwe \& Kassouf 2008), por um lado, e, por outro, sugere potenciais efeitos do trabalho infantil sobre a mobilidade intergeracional de renda e educação, isto é, sobre o acúmulo de capital humano da criança ao longo da vida e seu retorno salarial (Ilahi et al. 2000, Emerson \& Portela Souza 2002, Lopes \& Pontili 2010, Aquino et al. 2010). Nesse contexto, dados os potenciais efeitos do trabalho infantil sobre a transmissão intergeracional da pobreza, e, portanto, sobre o crescimento econômico e desenvolvimento do Brasil, o norteamento mais eficaz de políticas de combate à pobreza e desigualdade de renda não deve desconsiderar os possíveis determinantes daquele fenômeno.

Diante do exposto, o presente artigo tem como objetivo investigar os principais determinantes da incidência do trabalho infantil no Brasil urbano, considerando o controle de viés provocado por variáveis omitidas a partir do emprego de modelos empíricos desenhados para dados em painel. Dessa maneira, o estudo busca avançar em relação à literatura nacional ao isolar alguns importantes efeitos de demanda sobre o trabalho infantil, a exemplo do grau de informalidade e da estrutura dos mercados regionais.

$\mathrm{O}$ trabalho encontra-se dividido em cinco seções, incluindo essa introdução. A segunda trata da revisão da literatura econômica sobre trabalho infantil, destacando o papel da pobreza e da persistência intergeracional. A terceira faz uma explanação acerca da estratégia empírica adotada e sobre o tratamento dos dados. Na quarta, são apresentadas e discutidas as principais evidências desse estudo e, por fim, a última seção é reservada à conclusão.

\section{Revisão da Literatura}

Nesta seção, apresenta-se uma breve revisão da literatura econômica sobre o trabalho infantil, destacando-se importantes implicações teóricas e evidências empíricas nos âmbitos nacional e internacional. Por fim, faz-se um relato da experiência brasileira em políticas de combate ao trabalho infantil.

\subsection{A Persistência Intergeracional do Trabalho Infantil}

No arcabouço da teoria econômica existem vários modelos para a avaliação do trabalho infantil, no entanto, o mais difundido é o de Basu \& Van (1998). Esses autores destacam a relação entre pobreza e trabalho infantil, ao mostrar 
que o referido fenômeno é mais frequente em famílias pobres. Em particular, o modelo dos autores em destaque produz duas implicações relevantes: (i) os pais sempre colocam seus filhos para trabalhar quando o salário de mercado não possibilita o nível de consumo de subsistência; e (ii) a oferta de trabalho infantil de cada domicílio seria decrescente com o salário de mercado (Jafarey \& Lahiri 2005).

Recentemente, um tema que tem ganhado destaque na teoria econômica é a relação de escolha entre trabalho infantil e educação durante os anos de formação das crianças. Assume-se que nesse período da vida as decisões sobre a alocação do tempo das crianças são feitas pelos pais, portanto, sofrendo uma forte influência da estrutura familiar, da dotação de capital humano e da renda domiciliar. No entanto, ainda que a renda corrente dos pais esteja diretamente relacionada à qualificação, a existência de um prêmio pela educação (salário mais elevado quando adulto) permite discutir a relação entre o nível educacional de uma geração e o da seguinte. Em linhas gerais, pais que não estudaram teriam um nível de renda menor, e, portanto, a probabilidade de inserir os filhos precocemente no mercado de trabalho seria maior. Assim, a opção pelo trabalho infantil frente ao estudo pode afetar a acumulação de capital da criança ao longo de sua vida, influenciando o seu nível de renda quando adulta.

Alguns modelos teóricos ressaltam que a persistência relatada acima pode ser condicionada por uma armadilha da pobreza e destacam o impacto do trabalho infantil sobre a educação e a escolha profissional quando adulto (Banerjee \& Newman 1993, Barham et al. 1995, Basu 2000). Em particu ar, o modelo de Jafarey \& Lahiri (2005) apresenta uma boa formaliz ção da relação entre persistência intergeracional de educação, renda e trabalho infan il, conforme se discute a seguir.

Suponha que a economia começa no período $t=1$, quando existe um único adulto pai de uma criança que viverá por dois períodos. Segue-se que, em $t=2$, a criança torna-se um adulto e também produz um único filho, que por sua vez, terá dois períodos de vida; o processo se repete infinitas vezes ao longo do tempo. Nesse contexto, em cada período, os pais trabalham em tempo integral e são responsáveis pela decisão de alocação do tempo das crianças entre trabalho e estudo. As famílias, através do seu próprio trabalho, produzem um único tipo de produto que pode variar na quantidade agregada e no nível de habilidades, dependendo da escolha de educação corrente da criança e do nível de educação adquirido pelos pais no passado. Cada criança nasce com um nível de habilidades normalizado para a unidade. A educação aumenta as habilidades das crianças, mas com um período de defasagem. Logo, a criança que estuda $e_{t}$ unidades de tempo ${ }^{5}$ no período $t$, adquire um estoque de capital $h_{t+1} \geq 1$ no período $t+1$, isto é, uma criança que estuda mais tempo terá maior qualificação quando adulta. Portanto, a relação direta entre tempo gasto na escola e habilidade futura pode ser representada pela seguinte função de acumulação de capital humano:

$$
h_{t+1}=H\left(e_{t}\right)
$$

tal que a função $H$ tem as seguintes propriedades: $H^{\prime}>0, H(0)=1, H(1)=\bar{h}$.

A partir dessa formulação, pode-se dizer que há um nível de qualificação máxima, o qual pode ser alcançado pela frequência à escola em tempo inte-

\footnotetext{
${ }^{5} \mathrm{O}$ tempo total disponível para estudo e trabalho, em cada período, é normalizado para 1.
} 
gral durante a infância $\bar{h}$, e um nível mínimo (igual a 1), que equivale à não frequência escolar $\mathrm{H}(0)$. Dessa maneira, uma criança que estuda $e_{t}$ unidades de tempo gera $\left(1-e_{t}\right)$ unidades na produção doméstica no período $t$, enquanto um adulto tem produção igual ao seu nível de habilidade $h_{t}$, desde que exerça trabalho em tempo integral. A produção total da família em determinado período equivale ao seu salário ou renda naquele mesmo período.

Cada adulto tem uma função utilidade que depende do consumo e do tempo de estudo da criança no período corrente:

$$
U_{t}=u\left(c_{t}\right)+g\left(e_{t}\right)
$$

onde: $c_{t}$ representa o consumo doméstico em $t ; u$ é uma função positiva e côncava que mensura utilidade gerada pelo consumo; $g$ é uma função positiva e côncava que capta o bem estar do pai ao alocar o tempo do filho à escola. ${ }^{6}$ Logo, admite-se que a utilidade dos pais aumenta com o número de filhos educados, isto é, os pais valorizam a educação das crianças e são avessos ao trabalho infantil.

A equação 2 deverá ser maximizada condicionalmente à seguinte restrição orçamentária que limita o consumo corrente à renda gerada pelo trabalho doméstico:

$$
c_{t}=h_{t}+\left(1-e_{t}\right)
$$

Assume-se ainda que cada família consome toda a sua renda no período corrente, de modo que não existe poupança ou empréstimos. Portanto, a escolha do tempo ótimo de alocação da criança na escola, em cada período, implica satisfazer a seguinte condição de primeira ordem:

$$
u^{\prime}\left(h_{t+1}-e_{t}\right)=g^{\prime}\left(e_{t}\right)
$$

onde: $u^{\prime}$ e $g^{\prime}$ representam, respectivamente, as utilidades marginais do consumo e da educação para cada unidade adicional de tempo de estudo $e_{t}$ da criança.

A condição 4 indica que a escolha ótima da fração de tempo da criança na escola $e_{t}$ é dada pela igualdade entre a utilidade marginal do consumo e utilidade marginal da educação, sendo que o consumo corrente depende diretamente da qualificação dos pais, obtida no passado por meio dos estudos, por um lado, e, por outro, inversamente do tempo de estudo da criança. Ademais, dada à hipótese de utilidade marginal decrescente, a equação em destaque permite apreender o efeito da transmissão intergeracional da educação. Por exemplo, um pai que acumulou elevada habilidade $h_{t}$ no passado, registra baixa utilidade marginal do consumo, o que, segundo a equação 4 , implica uma escolha ótima maior para o tempo da criança na escola $e_{t}$ e vice-versa. Portanto, a referida transmissão intergeracional da educação sugere que, em última instância, a escolha ótima de alocação do tempo da criança na escola é uma função direta da instrução do pai, isto é, $e_{t}=f\left(h_{t}\right), f^{\prime}>0$.

Em linhas gerais, o modelo em análise prediz que pais mais educados optam por colocar os filhos na escola em tempo integral $f(\bar{h})=1$, enquanto aqueles sem instrução direcionam todo o tempo dos filhos ao trabalho infantil

\footnotetext{
${ }^{6}$ Esses últimos pressupostos implicam os seguintes sinais para derivadas de primeira e segunda ordem: $u^{\prime}>0, u^{\prime \prime}<0, g^{\prime}>0, g^{\prime \prime}<0$. Portanto, são consistentes com o pressuposto da utilidade marginal decrescente.
} 
$f(1)=0$. Logo, considerando a equação 1 juntamente com as relações supracitadas, deduz-se que o nível de habilidade das crianças quando adultas $h_{t+1}$ dependerá do estoque de capital humano acumulado pelo pai, conforme sintetizado pela equação de transmissão intergeracional abaixo:

$$
h_{t+1}=H\left(e_{t}\right)=H\left(f\left(h_{t}\right)\right)=G\left(h_{t}\right)
$$

onde: $G$ é uma função composta que combina as propriedades de $H$ e de $f$, isto é, $G^{\prime}>0, G(1)=1, G(\bar{h})=\bar{h}$.

\subsection{Trabalho Infantil: fatos estilizados}

A literatura empírica não reporta consenso no tocante aos determinantes do trabalho infantil. Os achados variam bastante entre diferentes países e regiões, conforme discutido a seguir. No entanto, a pobreza parece ser um fator comumente aceito como importante determinante do trabalho infantil, geralmente mensurada através da renda familiar.

No âmbito internacional, Grootaert \& Kandur (1995) sugerem que o risco de gerenciamento da renda familiar é um importante determinante da oferta de trabalho infantil. Nesse sentido, Ray (2002), por exemplo, estudou a entrada precoce no mercado de trabalho em Gana e os seus resultados mostraram que os determinantes do trabalho infantil variam consideravelmente entre áreas rurais e urbanas.

O estudo de Bhalotra \& Heady (2003), realizado para Gana e Paquistão, sugere que a pobreza não está relacionada ao aumento do trabalho infantil nas áreas rurais. Os autores mostram que as famílias proprietárias de áreas maiores de terra (mais ricas) tendem a utilizar mais intensamente a mão de obra dos filhos. Basu \& Tzannatos (2003) apontam, em estudo feito para China, Índia e Tailândia, que a incidência do trabalho infantil tende a diminuir quando as nações tornam-se mais ricas.

A pesquisa de Gunnarsson et al. (2006) avaliou os impactos do trabalho infantil sobre o desempenho escolar utilizando dados de alunos de terceira e quarta séries em nove países da América Latina. Os resultados indicaram que o trabalho infantil reduz o desempenho escolar. Nesse contexto, o problema ganha proporções de longo prazo, afetando o progresso econômico dos indivíduos e elevando as desigualdades de renda na sociedade como um todo. Já Edmonds \& Schady (2012), em pesquisa realizada no Equador, mostraram que o trabalho infantil é reduzido com o aumento da renda advinda de programas governamentais.

No Brasil, em estudo realizado pela presidência da república no ano de 1998, identificou-se que a participação das crianças na força de trabalho decresce com o nível de renda das famílias onde estão inseridas; a taxa de participação de menores é mais elevada na área rural do que na urbana; finalmente, no caso do Brasil urbano-metropolitano, as taxas de participação são mais elevadas no Sul e no Sudeste do que no Norte e no Nordeste (Brasil 1998).

Emerson \& Portela Souza (2002) analisaram dados da década de 90 e constataram que, no Brasil, existe uma relação inversa entre o nível de renda dos indivíduos adultos e a idade em que estes começaram a trabalhar. Já Ilahi et al. (2000) encontraram evidências que a inserção precoce no mercado de trabalho brasileiro diminui a frequência escolar e acarreta expectativa de renda baixa 
na idade adulta, comprometendo o desenvolvimento social e econômico do país.

Duryea \& Arends-Kuenning (2003), analisando a área urbana de 25 estados brasileiros, destacam que a taxa de emprego para crianças entre 14 e 16 anos aumenta quando o mercado de trabalho local apresenta condições favoráveis no tocante à remuneração e às oportunidades de emprego. Nesse cenário, o custo de oportunidade de manter a criança na escola aumenta, elevando a probabilidade de trabalhar.

Schwartzman \& Schwartzman (2004) destacaram que o trabalho das crianças brasileiras está associado à condição de pobreza, mas também é explicado pela tradição da agricultura familiar, principalmente na região Sul do país. Adicionalmente, mostraram que mesmo quando controlada a renda, residir na zona rural tem um efeito positivo sobre o trabalho infantil. Isto é, o trabalho infantil na zona rural não é o resultado apenas de um menor nível de renda, mas de uma infraestrutura escolar mais deficiente ou mesmo da inexistência de escolas, da maior facilidade com que a criança é absorvida em atividades informais que exigem menor qualificação e das atividades agrícolas familiares.

Cardoso \& Portela Souza (2004) mostraram que os programas de transferência de renda no Brasil não tiveram efeito significativo para a redução do trabalho infantil, mas um impacto positivo sobre a frequência escolar. Em geral, os programas sociais aumentam a chance de uma criança pobre ir para a escola, mas o benefício é relativamente menor que a renda do trabalho infantil, não incentivando a saída do mercado. ${ }^{7}$

Em um dos mais importantes estudos feitos no Brasil sobre as temáticas trabalho infantil e frequência escolar, Kassouf (2006) aponta que a entrada precoce dos pais no mercado de trabalho aumenta a probabilidade de a criança trabalhar. Recentemente, Lopes \& Pontili (2010) comprovaram, a partir de dados da PNAD de 2008, que na região Nordeste do Brasil, o trabalho infantil afeta negativamente tanto a escolaridade, quanto a renda dos trabalhadores adultos, isso porque quanto menor a idade em que uma pessoa começou a trabalhar, menor a probabilidade de concluir o ensino médio e/ou ter um salário acima da média da região. Assim, concluem que deve haver uma continuidade das políticas de combate ao trabalho infantil, especialmente no Nordeste, onde a renda obtida no mercado de trabalho é inferior a todas as outras. Seus resultados ainda corroboram o estudo anterior de Kassouf (2002), o qual mostrou que quanto mais cedo o indivíduo começa a trabalhar, menor é a sua escolaridade e o seu rendimento.

Aquino et al. (2010) apontam que o fato de os pais trabalharem na infância tem um efeito positivo e significativo sobre a probabilidade dos filhos trabalharem em áreas rurais e urbanas do Brasil, embora o impacto seja mais significativo nas áreas rurais. Destaca-se como um dos fatores determinantes para a redução do trabalho infantil a educação dos pais.

Ainda em pesquisa recente, Neves \& Menezes (2010) verificaram o efeito das transferências do Bolsa Família sobre o trabalho infantil no Nordeste e no Sudeste do Brasil. Os resultados mostraram que o programa se correlaciona tanto quanto a decisão de trabalhar quanto a de estudar, mas que o resultado é diferente entre as duas regiões estudadas, isto é, o efeito da redução do traba-

\footnotetext{
${ }^{7}$ Vale ressaltar que esse estudo foi realizado com dados do Censo de 2000, quando o Bolsa Família ainda não tinha sido adotado pelo Governo Federal.
} 
lho infantil e elevação da frequência escolar é mais significativo no Nordeste. O estudo ainda sugere que as crises econômicas atuam no sentido de substituição da mão de obra infantil pelos adultos menos qualificados, dado o aumento da taxa de desemprego.

Portanto, conforme a breve revisão acima, observa-se que a literatura sobre trabalho infantil relata a importância da renda, das características familiares e da estrutura do mercado de trabalho na decisão de oferta e demanda de trabalho, bem como suas particularidades entre regiões geográficas e zonas rural e urbana. Ademais, as consequências da entrada precoce no mercado de trabalho transbordam da infância para a fase adulta dos indivíduos, por meio dos efeitos sobre a acumulação de capital humano e remuneração do trabalho.

\subsection{A experiência brasileira em políticas de combate ao trabalho infantil}

De acordo com a Organização Internacional do Trabalho (OIT), desde a época da escravidão até os dias de hoje, o trabalho infantil está presente no Brasil (OIT 2001). Apesar desse histórico, o país vem seguindo uma tendência mundial de declínio do trabalho infantil nas últimas décadas, em grande parte devido à execução de programas sociais e ao desenvolvimento de políticas de combate ao trabalho infantil.

O trabalho infantil é um problema de natureza complexa e de difícil erradicação, sobretudo, por sua inter-relação com a pobreza, desigualdade de oportunidades e exclusão social, que são problemas de cunho estrutural e, portanto, depende de uma ampla transformação social para ser resolvido. No entanto, em virtude do seu impacto negativo sobre o crescimento econômico e criação de um ciclo de pobreza intergeracional, é importante o desenvolvimento de políticas sociais e econômicas de curto e de longo prazo.

As estratégias de combate ao trabalho infantil geralmente estão associadas a medidas de incremento de renda, desenvolvimento de leis mais eficazes de punição e fiscalização e campanhas de conscientização a respeito dos malefícios à criança no presente e no futuro, tornando a população um agente fiscalizador.

No Brasil, o combate ao trabalho infantil é uma questão de direitos humanos e envolve não apenas o governo, mas toda a sociedade. Na atualidade, a legislação trabalhista brasileira proíbe o trabalho de pessoas com menos de 16 anos de idade, a não ser na condição de aprendiz a partir dos 14 anos (MTE 2001). No entanto, uma das grandes dificuldades encontradas é a identificação, pois grande parte dos postos de trabalho está atrelada às atividades informais ou de difícil fiscalização, onde sua presença é sub-registrada. Vale ainda destacar o trabalho doméstico, que tem um papel importante nesse contexto, mas por tratar-se de aspecto cultural, muitas vezes não é considerado, pelas famílias, como trabalho.

A partir da década de 90, a atuação do governo tem sido mais intensa no combate ao trabalho infantil, seja através da aprovação de leis, do incentivo a ações de órgãos sociais e de programas de distribuição de renda. No ano de 1990, foi promulgado o Estatuto da Criança e do Adolescente (ECA); em 1992 o país aderiu ao Programa Internacional de Eliminação do Trabalho Infantil (IPEC) da Organização Internacional do Trabalho (OIT); em 1994 foi criado o Fórum Nacional de Prevenção e Erradicação do Trabalho Infantil, coorde- 
nado pelo Ministério do Trabalho, articulando ações de combate e integrando organizações governamentais (ONGs) e não governamentais (MTE 2001).

Já em 1996, foi assinado o protocolo denominado de Compromisso para Erradicação do Trabalho Infantil e Proteção ao Adolescente no Trabalho, que conta com a participação dos governos estaduais, confederações nacionais de empregadores, centrais sindicais, Confederação Nacional dos Trabalhadores na Agricultura, Programa Comunidade Solidária e várias ONGs. ${ }^{8}$ Em 1998, foi validada a Declaração sobre os Princípios e Direitos Fundamentais do Trabalho, que tem como um de seus princípios a efetiva abolição do trabalho infantil.

Para o Ministério do trabalho e do Emprego as intervenções do governo em favor da erradicação do trabalho infantil no Brasil, estão divididas em 6 grandes frentes: (i) sensibilização e mobilização social; (ii) integração e sistematização de dados; (iii) promoção da articulação institucional quadripartite (governo, organizações de trabalhadores e de empregadores e organizações não governamentais); (iv) fiscalização e denúncia contra a exploração da mão de obra infantil; (v) garantia de escola pública de qualidade; e (vi) incremento da renda. Dentre essas vertentes, o maior destaque, na atualidade, é para o incremento de renda. Nesse sentido, destacam-se o Programa de Erradicação do Trabalho Infantil (PETI) da Secretaria de Assistência Social/MPAS, criado em 1998, embora alcançando abrangência nacional apenas em 2001, e o Programa Bolsa Família, no ano de 2003.

O PETI é um Programa do Governo Federal que tem como objetivo retirar as crianças do mercado de trabalho, possibilitar o acesso e o bom desempenho das mesmas na escola, promover o acesso ao lazer e proporcionar apoio aos pais, através da execução de projetos de geração de trabalho e renda para as famílias. O programa oferece renda às famílias que mantém as crianças na escola, atividades de educação e cultura através do ensino integral. Também atua em conjunto com o Programa Nacional de Geração de Emprego e Renda em Áreas de Pobreza (PRONAGER) e Programa Nacional de Qualificação Profissional (PLANFOR). O primeiro gera ocupações produtivas e renda para as comunidades carentes e o segundo prioriza ações de formação e qualificação profissional nas famílias e áreas onde há registro de trabalho infantil.

No ano de 2001, o governo implementou o programa Bolsa Escola Federal, que oferecia uma complementação de renda às famílias, associado à manutenção da criança na escola. O público-alvo do programa eram as famílias com renda mensal per capita inferior a meio salário mínimo, com filhos ou dependentes entre 6 e 15 anos. Em 2003, houve a criação do Programa Bolsa Família que beneficia famílias em situação de pobreza e extrema pobreza através de transferências diretas de renda com condicionalidades. O programa integrou e unificou ao Fome Zero ${ }^{9}$ as iniciativas "Bolsa Escola", "Auxílio Gás" e "Cartão Alimentação". A partir de 2011, o Bolsa Família tornou-se uma das estratégias do Plano Brasil Sem Miséria (BSM), atuando no eixo da geração de

\footnotetext{
${ }^{8}$ Entre as entidades não governamentais, destaca-se a fundação ABRINQ, que desenvolve vários projetos de combate ao trabalho infantil, a exemplo dos projetos: o Prefeito Amigo da Criança, Projeto Adotei um Sorriso (SP), Projeto Empresa Amiga da Criança, Projeto Jornalista Amigo da Criança entre outros.

${ }^{9}$ O Fome Zero é uma estratégia do governo federal que tem como objetivo principal garantir segurança nutricional as pessoas com dificuldades de acesso aos alimentos, através de 4 eixos de atuação, quais sejam, acesso à alimentação, geração de renda, fortalecimento da agricultura familiar e articulação, mobilização e controle social.
} 
renda. Nesse contexto, vale salientar que embora o Bolsa Família não tenha como objetivo direto a erradicação do trabalho infantil, a sua atuação sobre a frequência escolar e elevação do nível de renda, pode gerar impactos positivos no combate do mesmo.

Apesar de as políticas públicas apresentarem resultados positivos na última década, em virtude do papel estrutural do trabalho infantil, ainda há muito a ser feito. De acordo com Silveira et al. (2000), devem-se priorizar não apenas políticas de distribuição de renda, mas políticas de elevação do nível de renda da população como um todo, como por exemplo, redução da taxa de desemprego e políticas efetivas de salário mínimo. Por outro lado, é necessária a melhoria da infraestrutura educacional e redução dos custos de acesso à escola, e ainda maior eficiência no aparato jurídico-institucional, de modo a aumentar a eficácia no cumprimento das normas legais referentes ao trabalho infantil.

\section{Estratégia Empírica}

Esta seção é reservada à estratégia empírica do presente estudo e encontrase organizada em duas partes. Primeiro, são apresentadas especificações de modelos econométricos empregados na investigação dos principais determinantes do trabalho infantil no Brasil, considerando diferentes controles para a heterogeneidade não observada. Em seguida, aborda-se o tratamento dos dados e seleção de variáveis utilizadas nas estimações econométricas.

\subsection{Modelos Econométricos}

A literatura econométrica ressalta que os modelos econométricos aplicados a dados em painel permitem controlar fatores não observados que estariam correlacionados a determinado conjunto de variáveis (Baltagi 2008, Wooldridge 2010). Dessa maneira, no intuito de identificar o impacto dos principais determinantes do trabalho infantil no Brasil, serão consideradas, além dos clássicos modelos lineares com efeitos fixos ou aleatórios, regressões com variáveis instrumentais e modelos dinâmicos. Inicialmente, tome-se o seguinte modelo de regressão linear:

$$
y_{i t}=x_{i t} \beta+\mu_{i}+u_{i t}
$$

onde: $y_{i t}$ é a taxa de crianças trabalhadoras na unidade federativa $i$ e no ano $t ; x_{i t}$ é um vetor de variáveis explicativas que afetam a alocação das crianças no mercado de trabalho e captura diferenças estruturais entre os estados ao longo do tempo; $\beta$ é um vetor de parâmetros a ser estimado (inclusive intercepto); $\mu_{i}$ representa um conjunto de variáveis não observadas específicas a cada unidade federativa; $u_{i t}$ é um termo estocástico com média zero, variância constante e não correlacionado no tempo.

Conforme destacado por Cameron \& Trivedi (2005), a estimativa de 6, diretamente pelo método dos Mínimos Quadrados Ordinários (MQO), não permite estimativas consistentes dos seus parâmetros, uma vez que $\mu_{i}$ pode estar correlacionado com $x_{i t}$. Para contornar esse problema, algumas hipóteses devem ser feitas no tocante à heterogeneidade não observada. Primeiro, se o conjunto de variáveis não observadas $\mu_{i}$ for interpretado como um termo fixo 
no tempo, ${ }^{10}$ contudo, variante entre as unidades federativas e correlacionado com $x_{i t}$, a estimativa da equação 6 por MQO, em primeira diferença na média (estimador de efeitos fixos ou within), permite parâmetros consistentes sob a hipótese de não aleatoriedade de $\mu_{i}$. Segundo, se o termo $\mu_{i}$ específico a cada estado for tratado como estocástico e não correlacionado com variáveis observadas, o conhecido estimador de efeitos aleatórios fornecerá parâmetros consistentes e eficientes em grandes amostras ${ }^{11}$ (Wooldridge 2010).

Outro problema que precisa ser considerado é o viés induzido pela potencial endogeneidade de alguns regressores na equação 6. Mais especificamente, o vetor de variáveis explicativas da referida equação pode incluir alguns componentes interdependentes do trabalho infantil. A renda domiciliar é um exemplo típico. Sabe-se que essa variável desempenha um papel importante na determinação da alocação do tempo das crianças entre estudo e trabalho, e que a mesma pode ser afetada pelos rendimentos auferidos com o trabalho infantil e/ou com o número de trabalhadores na família. Dessa maneira, neste estudo foram empregadas duas estratégias na tentativa de superar as dificuldades reportadas: (i) regressões com estimadores de efeitos fixos e de efeitos aleatórios usando variáveis instrumentais ${ }^{12}$ e (ii) regressões com estimadores de Arellano \& Bond (1991) e Blundell \& Bond (1998) na classe dos modelos dinâmicos.

Em particular, a estimativa de modelos dinâmicos para dados em painel permite, adicionalmente, testar a presença de persistência temporal do trabalho infantil. Considere-se a seguinte versão dinâmica do modelo 6 :

$$
y_{i t}=\theta y_{i t-1}+x_{i t} \beta+\mu_{i}+u_{i t}
$$

onde: $y_{i t-1}$ é a taxa de crianças trabalhadoras do estado $i$ e no ano $t-1$ e $\theta$ é um parâmetro restrito $|\theta|<1$.

A presença da variável dependente defasada $y_{i t-1}$ no modelo 7 torna-o autorregressivo e permite capturar a dinâmica temporal do trabalho infantil, sob a ausência de autocorrelação serial do termo de erro $u_{i t}$. Nesse sentido, o modelo é consistente com a hipótese de fricções/ajustes lentos nos mercados de trabalho.

Desse modo, Arellano \& Bond (1991) propõem estimar 7 em primeira diferença usando o Método dos Momentos Generalizados (GMM), no qual o vetor $x_{i t}$ inclui um conjunto de variáveis exógenas, sejam contemporâneas (em $t$ ) ou defasadas (predeterminadas em $t-1, t-2, \ldots$ ) e variáveis instrumentais $z_{i t} \subset x_{i t}$, as quais permitem controlar possíveis problemas de endogeneidade no modelo. ${ }^{13}$ Já Blundell \& Bond (1998), por sua vez, incorporam outras con-

\footnotetext{
${ }^{10}$ A equação 6 pode não incluir variáveis que possivelmente afetam o trabalho infantil, a saber: externalidades locais, fatores sociais relacionados à distribuição de renda etc. Ao se interpretar esse conjunto de variáveis omitidas como externalidades e/ou amenidades, é razoável supor que suas mudanças no tempo ocorrem lentamente.

${ }^{11}$ Para uma visão detalhada sobre os estimadores de efeitos fixos e de efeitos aleatórios o leitor pode consultar Baltagi (2008, p.11-31) e Wooldridge (2010, p. 281-328). Vale ainda ressaltar que o teste de Hausman fornece um critério estatístico para a escolha entre os estimadores de efeitos fixos e aleatórios (vide Apêndice A).

${ }^{12}$ Para maiores detalhes, consultar Wooldridge (2010, p. 281-328).

${ }^{13}$ A transformação da equação 7 em primeira diferença elimina efeitos específicos não observados. Todavia, o tratamento da correlação entre as variáveis $\Delta y_{i t-1}$ (diferença da variável dependente defasada) e $\Delta u_{i t}$ (diferença dos resíduos) envolve um conjunto de variáveis defasadas a partir de $t-2$, derivadas a partir de um grande número de condições de momentos entre variáveis instrumentais e primeira diferença dos resíduos $E\left(z_{i t} \Delta u_{i t}\right)=0$. Uma boa discussão sobre as
} 
dições de momentos na estimativa GMM, as quais são derivadas da correlação entre as variáveis independentes e o termo de erro do modelo 7 e permitem usar variáveis em primeiras diferenças defasadas como instrumentos adicionais. Logo, dadas suas propriedades desejáveis, o estimador Blundell-Bond também será empregado nesse estudo. ${ }^{14}$

\subsection{Base de Dados e Tratamentos}

Os dados utilizados nesse estudo provêm de um painel construído a partir dos dados da Pesquisa Nacional por Amostra de Domicílios (PNAD) elaborada, anualmente, pelo Instituto Brasileiro de Geografia e Estatística (IBGE).

A PNAD, embora forneça um leque considerável de informações socioeconômicas das pessoas entrevistadas e guarde maior periodicidade em relação aos Censos Demográficos, não acompanha os mesmos indivíduos ao longo do tempo. Também não oferece informações desagregadas a partir de municípios e/ou microrregiões. Assim, os dados longitudinais disponíveis se limitam às unidades federativas e aos meios rural e urbano do Brasil.

Diante das referidas restrições, e com vistas a atender o objetivo do presente estudo, tornou-se possível construir um painel de dados a partir de informações estaduais sobre trabalho infantil e suas variáveis determinantes durante o período de 2001 a 2009. Esse último período foi escolhido por fornecer dados mais atualizados e consoantes com mudanças importantes na economia brasileira, a saber: aumento da real renda do trabalho e estabilidade de preços. Os dados por estado foram restritos ao meio urbano, por acreditar-se que nesse espaço o trabalho infantil é mais influenciado por fatores econômicos, ao contrário do meio rural, onde aspectos culturais/familiares podem desempenhar um papel importante. ${ }^{15}$

Desse modo, as seguintes variáveis foram construídas a partir do cruzamento das informações prestadas pelos domicílios entrevistados, estado de residência e setor do domicílio: (a) taxa de crianças trabalhadoras - razão entre crianças de 10 a 14 anos de idade que se achavam trabalhando e o total de crianças na mesma faixa etária que residem no meio urbano estadual; (b) renda média - média da renda domiciliar per capita na zona urbana estadual; ${ }^{16}$ (c) idade de entrada - idade média que os adultos com 25 anos ou mais começaram a trabalhar; (d) grau de informalidade — total de trabalhadores com 16 anos ou mais empregados em ocupações informais no meio urbano em rela-

propriedades dos estimadores GMM e Arellano-Bond pode ser encontrada em Cameron \& Trivedi (2005, p.744-767).

${ }^{14}$ É importante ressaltar que a consistência e eficiência dos estimadores Arellano-Bond e Blundell-Bond estão sujeitas ao seguinte conjunto de restrições: (i) ausência de autocorrelação temporal do erro estocástico; (ii) exogeneidade fraca das variáveis. A validade desses pressupostos pode ser verificada, respectivamente, pelo teste de Arrelano-Bond para autocorrelação dos resíduos e pelo teste de Sargan para sobreidentificação de variáveis instrumentais (vide Cameron \& Trivedi 2005, Wooldridge 2010). Outra hipótese implícita é que o painel de dados é estacionário (há ausência de raiz unitária), o que implica ausência de relações espúrias nas regressões. Todavia, essa hipótese pode ser testada com precisão apenas em painéis de dimensão temporal moderada, isto é, com ao menos 30 períodos de tempo (Cameron \& Trivedi 2005, Baltagi 2008).

${ }^{15}$ Essa opção também é reforçada pela necessidade de aumentar a amostra do estudo, uma vez que, antes de 2004, as PNADs não entrevistavam moradores do meio rural da região Norte.

${ }^{16}$ Os valores monetários foram ajustados para reais de setembro de 2009 conforme o INPC e os outliers identificados foram excluídos do cálculo da média por estado. A renda média foi tomada em logaritmo para reduzir sua variância e manter conformidade com a escala da variável dependente do modelo empírico (taxa de crianças trabalhadoras). 
ção ao total de ocupações; ${ }^{17}$ (e) escolaridade — média de anos de estudos da população com 25 anos ou mais residente no meio urbano dos estados (variável instrumental) e (f) cobertura do bolsa família - razão entre o número de domicílios beneficiados pelo Programa Bolsa Família e o número de domicílios candidatos a receber o benefício em cada estado (público-alvo). ${ }^{18}$ Vale ressaltar que esse conjunto de variáveis é consoante com aquelas empregadas na literatura empírica e buscam captar potenciais efeitos condicionados ao nível de pobreza, persistência intergeracional do trabalho infantil, grau de informalidade das atividades econômicas e transferências de renda. A Tabela B.2, no Apêndice, registra as estatísticas descritivas das variáveis elencadas anteriormente.

\section{Análise dos resultados}

A presente seção apresenta os resultados desse estudo e se acha dividida em duas partes. Na primeira, é realizada uma exploração estatística acerca da evolução da frequência escolar e do trabalho infantil no Brasil buscando-se evidenciar diferentes padrões regionais. Ademais, também são investigadas correlações entre a intensidade do trabalho infantil nos estados brasileiros e um conjunto de variáveis selecionadas no painel de dados, a saber: renda média, idade de entrada dos adultos no mercado de trabalho, grau de informalidade dos mercados de trabalho e proporção de famílias beneficiadas pelo Programa Bolsa Família. Finalmente, na segunda parte, são apresentados e discutidos os resultados empíricos referentes aos principais determinantes do trabalho infantil no Brasil.

\subsection{A Evolução do trabalho infantil e da frequência escolar no Brasil}

Atualmente, o trabalho infantil tem sido visto como um impedimento ao progresso econômico, principalmente, devido ao impacto negativo sobre o estoque de capital humano das crianças. A partir da década de 90, o percentual de crianças trabalhadoras sofreu um declínio no Brasil e no mundo, resultado da intensificação das políticas de combate ao trabalho infantil em conjunto com o desenvolvimento de programas sociais de distribuição de renda com condicionalidades, os quais têm como objetivo retirar as crianças do mercado de trabalho e aumentar a frequência escolar.

No Brasil, durante os últimos 14 anos, os dados das PNADs apontam uma trajetória de declínio no percentual de crianças entre 10 e 14 anos que ocupam algum tipo de atividade econômica (remunerada ou não). Conforme pode ser visto na Figura 1, a seguir, em 1995, o referido percentual era cerca de $18 \%$, passando para $7 \%$ em 2009, isto é, uma redução considerável de 11 pontos percentuais. Em contrapartida, observa-se uma tendência de universalização do acesso ao ensino fundamental, uma vez que em 2009, aproximadamente

\footnotetext{
${ }^{17}$ As seguintes ocupações foram consideradas como informais: empregado sem carteira de trabalho assinada, empregado por conta própria, empregado em ajuda ao próprio domicílio ou para o próprio consumo. Já os empregados com carteira de trabalho assinada, empregadores ou funcionários públicos foram agrupados como trabalhadores do setor formal.

${ }^{18}$ Os dados referentes às famílias beneficiadas foram obtidos no IPEADATA. As famílias com renda domiciliar igual ou inferior a $\mathrm{R} \$ 140$ a preços constantes de 2009 e com crianças com 17 anos ou menos de idade foram classificadas como público-alvo a partir dos dados das PNADs. Entre os anos de 2001 e 2003, a variável Bolsa Família registra valor zero dada a inexistência do próprio Programa, e, portanto, de famílias beneficiadas.
} 
98\% das crianças estavam frequentando escola ou creche, crescimento de 10 p.p. em relação a 1995.

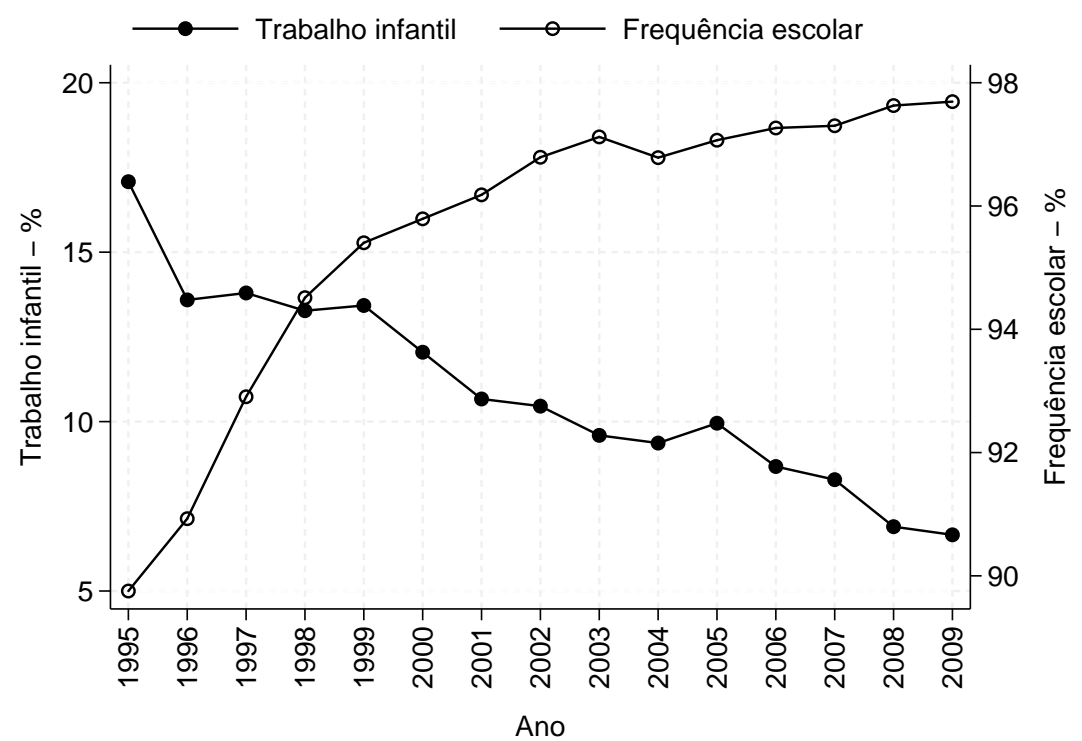

Fonte: Elaboração própria a partir da Pesquisa Nacional por Amostras de Domicílios (PNAD): 1995-2009.

Notas: Dados expandidos para o universo. Para o ano 2000, as taxas foram ajustadas por interpolação linear.

Figura 1: Brasil - Evolução das taxas de trabalho infantil e de frequência escolar (1995-2009) — \%

O período em análise foi marcado por melhorias nas condições de vida da população como um todo. O nível de renda apresentou ganhos reais, resultado que pode ser atribuído ao crescimento econômico, estabilidade de preços e programas de transferência de renda. Segundo dados do Instituto de Pesquisas Econômicas Aplicadas (IPEA), o índice de Gini no Brasil, que mede a concentração de renda, evoluiu de 0,60 para 0,54 entre os anos de 1995 e $2009,{ }^{19}$ enquanto a renda domiciliar per capita, passou de $\mathrm{R} \$ 579,92$ para $\mathrm{R} \$ 705,72$, no mesmo período. Ainda segundo dados do IPEA, desde o ano de 2003 a taxa de famílias em condição de extrema pobreza vem registrando queda considerável, passando de 11,3\% no referido ano para 5,8\% em 2009. Considerando que a pobreza é um dos mais importantes determinantes do trabalho infantil, nações que se tornam mais ricas devem apresentar redução nos índices aferidores desse fenômeno (Basu \& Tzannatos 2003).

Em conjunto com as melhoras econômicas, as políticas de combate ao trabalho infantil também apresentaram mudanças significativas, juntamente com a criação de programas de distribuição de renda. No ano de 2001, foi criado o Programa Bolsa Escola, que em 2003, incluindo outros programas do governo (Cartão Alimentação, Bolsa Alimentação e Auxílio-Gás), passou a ser chamado de Bolsa Família. Sua principal característica é a distribuição de

${ }^{19} \mathrm{O}$ índice de Gini varia de 0 a 1. Quanto mais próximo de 1, maior a concentração de renda. 
renda às famílias pobres, tendo como uma de suas contrapartidas, a frequência escolar das crianças. Em 2010, o programa em destaque beneficiou cerca de 12,4 milhões de famílias em todo o Brasil. Cabe ainda destacar a expansão do Programa de Erradicação do Trabalho Infantil (PETI) para todo o Brasil a partir de 2003, que além de ter fornecido renda às famílias, ofereceu oportunidade de qualificação para os pais e escola integral para as crianças.

No tocante à frequência escolar, segundo Fernandes \& Portela Souza (2003), a sua expansão está intimamente ligada à redução do trabalho infantil. Nesse contexto, a maior parte dos estudos empíricos fornece evidências sobre a eficácia do programa Bolsa Família em termos da expansão da frequência escolar (Cardoso \& Portela Souza 2004, Cacciamali et al. 2010, Neves \& Menezes 2010) Glewwe \& Kassouf (2008), por exemplo, apontam que o referido programa foi responsável pelo aumento das matrículas do ensino fundamental, pela redução da taxa de abandono escolar e elevação da taxa de aprovação. Já para Santos \& Portela Souza (2007), o aumento da frequência escolar se deu pela melhora na qualidade e no acesso as escolas de ensino público ao longo da década de 90, assim como, pelas mudanças no background familiar.

Outro aspecto de relevância, observado a partir dos dados das PNADs, é que o trabalho infantil apresenta diferentes características entre as regiões rurais e urbanas no Brasil. Em áreas rurais, o fator cultural parece ser muito forte. Por exemplo, entre as famílias rurais, existe a tradição dos pais passarem o ofício para os filhos, principalmente na agricultura. Kassouf (2007) sugere que a infraestrutura escolar mais fraca e a menor taxa de inovação tecnológica podem desencorajar a frequência escolar e promover com maior facilidade a absorção das crianças em atividades informais demandantes de baixa qualificação. Na zona urbana, o trabalho infantil seria um meio de sobrevivência para famílias de baixa renda, ao permitir maiores oportunidades de trabalho e de remuneração (Duryea \& Arends-Kuenning 2003).

Na Figura 2, é possível observar que, apesar da tendência de queda ao longo dos últimos anos, o trabalho infantil é bem mais presente nas áreas rurais do que nas urbanas. No entanto, o ritmo de queda é mais acentuado na zona rural, onde, entre 1995 e 2009, a taxa de crianças trabalhadoras entre 10 e 14 anos de idade passou de $43 \%$ para aproximadamente $17 \%$. Ainda é possível observar que, na zona urbana, a trajetória de redução do trabalho infantil ocorreu de forma mais moderada.

Apesar de os estudos internacionais mostrarem que o trabalho infantil diminui com o aumento da renda promovida por programas governamentais (Edmonds \& Schady 2012), no Brasil ainda não há consenso. Segundo Cacciamali et al. (2010), o fato de ser beneficiário do Bolsa Família aumenta a probabilidade de incidência de trabalho infantil nos domicílios pobres. Esse fato estaria relacionado à própria condição de pobreza das famílias beneficiadas, que ainda necessitam da renda oriunda do trabalho infantil para garantir a sobrevivência. Cardoso \& Portela Souza (2004) apontam que os programas de transferência de renda no Brasil não tiveram efeito significativo sobre o trabalho infantil, considerando que as transferências representam um incentivo financeiro pequeno para promover o abandono da fonte de renda disponibilizada por aquele instrumento. Por outro lado, o Bolsa Família teve um impacto significativo na redução da pobreza no Brasil, um dos importantes determinantes da oferta de mão de obra infantil, dessa forma, seu efeito pode ser indireto.

O impacto do programa Bolsa Família parece apresentar diferenças mar- 


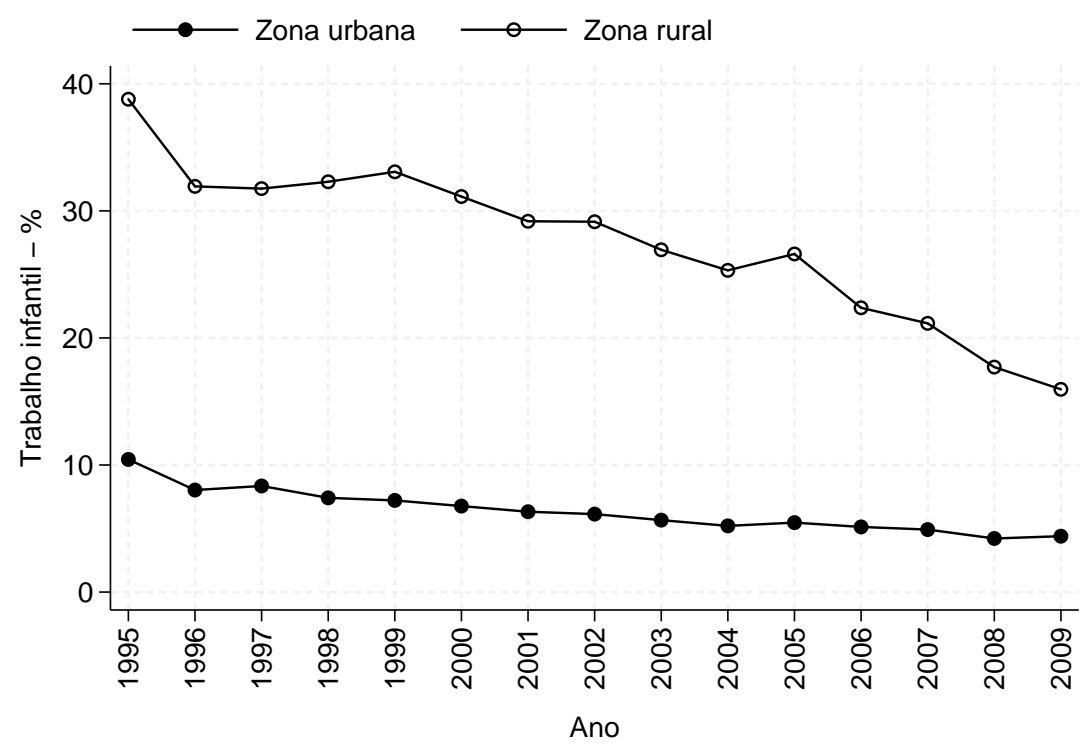

Fonte: Elaboração própria a partir da Pesquisa Nacional por Amostras de Domicílios (PNAD): 1995-2009.

Notas: Dados expandidos para o universo. Para o ano 2000, as taxas foram ajustadas por interpolação linear.

Figura 2: Brasil - Evolução da taxa de crianças trabalhadoras por setor domiciliar (1995-2009) — \%

cantes entre as zonas rural e urbana (Cardoso \& Portela Souza 2004). No campo, as crianças acabam trabalhando e estudando, muitas ajudam os pais na colheita sem remuneração, o que muitas vezes nem é considerado como trabalho infantil pela família, e com a tolerância de $15 \%$ de faltas não perdem o benefício. Já na zona urbana, as atividades desenvolvidas pelas crianças são permanentes, na maioria das vezes no setor informal. Não obstante, na cidade o custo de vida geralmente é maior que no meio rural e existem melhores oportunidades de trabalho e remuneração. Em muitos casos, o que a criança ganha trabalhando é bem maior que o benefício fornecido pelo Governo. Dessa forma, o custo de oportunidade de manter a criança na escola parece ser maior que nas áreas rurais.

Além da região censitária, as diferenças estruturais no mercado de trabalho por estado e região geográfica parecem alterar a distribuição do tempo das crianças entre estudo e trabalho. Segundo Duryea \& Arends-Kuenning (2003), um mercado de trabalho com melhores níveis de remuneração e oportunidades para as crianças aumenta o custo de oportunidade de estudar, favorecendo o trabalho infantil. Para Neves \& Menezes (2010), a remuneração e o grau de formalidade do mercado de trabalho afetam significativamente a oferta e a demanda por trabalho infantil.

Outra questão importante é o nível e a distribuição de renda entre as regiões, fatores que atuam sobre um dos principais determinantes do trabalho infantil, a pobreza (Basu \& Van 1998, Basu \& Tzannatos 2003). Nesse sentido, a Tabela 1 apresenta uma comparação entre as taxas de frequência escolar e de trabalho infantil por estados brasileiros, considerando os dados das PNADs 
de 2004 a $2009^{20}$ e crianças na faixa etária de 10 a 14 anos.

Tabela 1: Brasil — Taxas de Trabalho Infantil e de Frequência escolar por estados (\%)

\begin{tabular}{|c|c|c|c|c|c|}
\hline \multirow[b]{2}{*}{ Estado } & \multicolumn{2}{|c|}{2004} & \multirow[b]{2}{*}{ Estado } & \multicolumn{2}{|c|}{2009} \\
\hline & $\begin{array}{l}\text { Trabalho } \\
\text { Infantil }\end{array}$ & $\begin{array}{l}\text { Frequência } \\
\text { Escolar }\end{array}$ & & $\begin{array}{l}\text { Trabalho } \\
\text { Infantil }\end{array}$ & $\begin{array}{l}\text { Frequência } \\
\text { Escolar }\end{array}$ \\
\hline Piauí & 22,8 & 97,0 & Rondônia & 14,8 & 97,1 \\
\hline Maranhão & 19,2 & 95,6 & Piauí & 14,7 & 98,1 \\
\hline Rondônia & 18,7 & 93,7 & Tocantins & 14,6 & 98,4 \\
\hline Acre & 17,4 & 93,0 & Ceará & 12,5 & 98,0 \\
\hline Paraíba & 17,2 & 96,3 & Bahia & 12,3 & 97,8 \\
\hline Pará & 16,4 & 94,8 & Acre & 11,3 & 97,7 \\
\hline Bahia & 15,4 & 95,2 & Maranhão & 10,1 & 98,6 \\
\hline Ceará & 14,3 & 96,9 & $\begin{array}{l}\text { Rio Grande do } \\
\text { Norte }\end{array}$ & 9,7 & 95,8 \\
\hline Pernambuco & 13,6 & 94,9 & Pernambuco & 9,4 & 96,0 \\
\hline $\begin{array}{l}\text { Rio Grande do } \\
\text { Sul }\end{array}$ & 13,4 & 97,7 & Alagoas & 9,0 & 95,3 \\
\hline Tocantins & 13,3 & 96,9 & Goiás & 8,9 & 98,4 \\
\hline Mato Grosso & 13,3 & 95,9 & Mato Grosso & 8,9 & 97,5 \\
\hline Santa Catarina & 13,0 & 98,3 & Santa Catarina & 8,8 & 97,7 \\
\hline Alagoas & 12,2 & 95,1 & Pará & 8,4 & 96,5 \\
\hline Paraná & 11,4 & 96,7 & Minas Gerais & 8,1 & 97,7 \\
\hline Espírito Santo & 10,0 & 97,2 & $\begin{array}{l}\text { Rio Grande do } \\
\text { Sul }\end{array}$ & 6,7 & 98,5 \\
\hline Amazonas & 9,1 & 94,3 & Sergipe & 6,5 & 97,3 \\
\hline $\begin{array}{l}\text { Rio Grande do } \\
\text { Norte }\end{array}$ & 9,1 & 96,6 & Paraná & 6,4 & 96,8 \\
\hline Roraima & 9,0 & 97,9 & Amazonas & 6,1 & 96,3 \\
\hline Goiás & 8,5 & 96,9 & Paraíba & 5,7 & 97,9 \\
\hline $\begin{array}{l}\text { Mato Grosso do } \\
\text { Sul }\end{array}$ & 8,3 & 97,3 & Espírito Santo & 5,4 & 97,5 \\
\hline Minas Gerais & 7,7 & 97,2 & $\begin{array}{l}\text { Mato Grosso do } \\
\text { Sul }\end{array}$ & 5,2 & 97,7 \\
\hline Sergipe & 6,9 & 96,4 & Amapá & 3,6 & 97,2 \\
\hline São Paulo & 3,1 & 98,1 & São Paulo & 2,6 & 98,1 \\
\hline Amapá & 3,0 & 97,3 & Roraima & 2,2 & 98,7 \\
\hline Rio de Janeiro & 1,8 & 98,0 & Rio de Janeiro & 1,6 & 98,7 \\
\hline Distrito Federal & 0,8 & 98,1 & Distrito Federal & 1,5 & 98,5 \\
\hline
\end{tabular}

Fonte: Elaboração própria a partir da Pesquisa Nacional por Amostra de Domicílios (PNAD): 2004 e 2009.

Nos dois períodos de análise destacados na referida Tabela, os estados com maiores taxas de crianças trabalhadoras do Brasil estão nas regiões Norte e Nordeste, fato consoante com suas posições relativas de atraso econômico frente às demais regiões brasileiras. Destaca-se o estado do Piauí, que apesar da redução de $22,8 \%$ para $14,7 \%$, no quadro geral, passou de primeiro para segundo lugar, e o Distrito Federal que apesar do leve aumento na taxa de crianças trabalhadoras, continua em último lugar, com 1,5\%. As mudanças mais significativas foram no estado da Paraíba, de $17,2 \%$ para 5,7\%, passando da quinta para a vigésima colocação; em Roraima, que passou de 9\% para 2,2\%; e em Rondônia, que apesar da redução de 18,7\% para 14,8\%, em 2009 foi o estado com maior percentual de trabalho infantil do Brasil.

\footnotetext{
${ }^{20}$ Nessa Tabela, optou-se por considerar 2004 como ano base, pois foi a partir desse ano que a PNAD passou a incorporar entrevistas para os moradores da zona rural dos estados da região Norte.
} 
No intuito de expor uma investigação inicial acerca das relações entre a intensidade do trabalho infantil nos estados brasileiros e um conjunto selecionado de variáveis, as próximas figuras apresentam gráficos de dispersão considerando a evolução temporal. Sob tal perspectiva também é possível apreender padrões de regularidade entre correlações no tempo. A Figura 3 mostra a correlação linear entre a proporção de crianças trabalhadoras em áreas urbanas e a média da renda domiciliar per capita por estados do Brasil para os anos de 2001 a 2009. ${ }^{21}$ Conforme pode ser observado, há uma correlação linear negativa entre as referidas variáveis, isto é, os estados com menor renda per capita também são os que apresentam maior concentração de trabalho infantil.

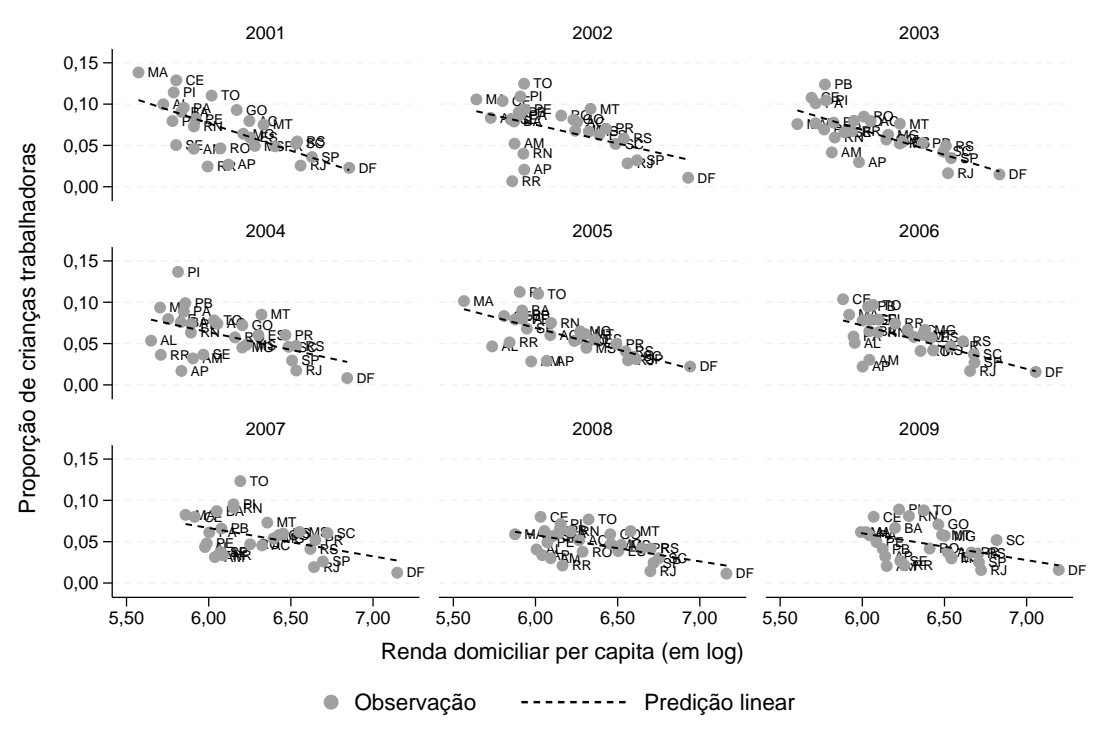

Fonte: Elaboração própria a partir dos dados da Pesquisa Nacional por Amostra de Domicílios (PNADs).

Figura 3: Brasil - Correlação linear entre a proporção de crianças trabalhadoras e a renda domiciliar per capita por estados (2001-2009)

Na Figura em análise, ainda é possível constatar que a maior parte dos estados das regiões Sul, Sudeste e Centro-Oeste, registra maiores níveis de renda e, consequentemente, menor participação de crianças trabalhadoras, ao contrário do observado para os estados das regiões Norte e Nordeste. Mais especificamente, o Distrito Federal, São Paulo e Rio de Janeiro apresentam baixa proporção de crianças trabalhadoras, enquanto os estados mais pobres como Piauí, Ceará e Maranhão, registram taxas mais elevadas. Isto é, os dados sugerem que nos estados mais ricos o efeito riqueza, gerado pelo maior nível de renda das famílias, parece superar o custo de oportunidade de estudar, uma vez que nos centros urbanos desses mesmos estados há melhores oportunidades de emprego e remuneração para as crianças.

\footnotetext{
${ }^{21}$ Valores ajustados para reais de 2009 conforme o Índice Nacional de Preços ao Consumidor (INPC).
} 
Outro aspecto importante é o potencial impacto do trabalho infantil sobre o ciclo intergeracional de pobreza. Segundo Ilahi et al. (2000) e Emerson \& Portela Souza (2002), o trabalho infantil é um importante determinante do nível de renda na fase adulta. A Figura 4, a seguir, apresenta a correlação linear entre a idade em que os adultos (pessoas com 25 anos de idade ou mais) começaram a trabalhar e proporção de trabalho infantil por estados brasileiros. Os dados mostram uma correlação inversa, isto é, nos estados onde a média de idade de entrada dos adultos no mercado de trabalho é maior, verifica-se baixa proporção de crianças trabalhadoras, padrão que se repete ao longo dos 9 anos de análise.

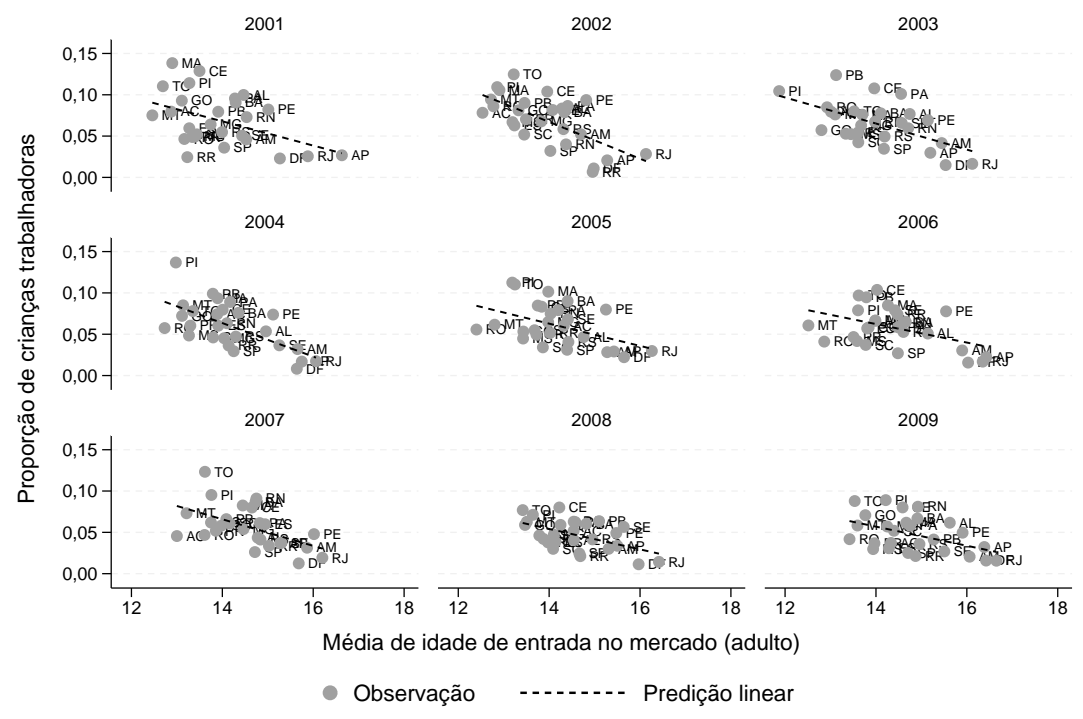

Fonte: Elaboração própria a partir dos dados da Pesquisa Nacional por Amostra de Domicílios (PNADs).

Figura 4: Brasil - Correlação entre a proporção de crianças trabalhadoras e a idade de entrada dos adultos no mercado de trabalho por estados

Dessa forma, as evidências apresentadas na Figura em foco sugerem que a inserção precoce no mercado de trabalho pode ter um impacto negativo sobre o acúmulo de capital humano, o que pode resultar em menor nível de renda na fase adulta. Assim, pais com baixo nível de renda tendem a colocar seus filhos para trabalhar, gerando um ciclo intergeracional de pobreza (Basu \& Van 1998, Basu \& Tzannatos 2003).

A Figura 5 apresenta correlações lineares entre a intensidade de trabalho infantil e a participação dos empregos informais no total de ocupações por estado (pessoas com 17 anos de idade ou mais) no período de 2001 a 2009. Percebe-se uma associação positiva entre as referidas variáveis, a qual se mostra regular ao longo do período em foco.

Nos estados do Piauí, Maranhão e Ceará, onde, em geral, os empregos informais representam cerca de $40 \%$ das ocupações, por exemplo, a taxa de trabalho infantil é relativamente maior que nas demais unidades federativas, fato oposto ao observado para os estados de Santa Catarina, São Paulo e o Distrito 


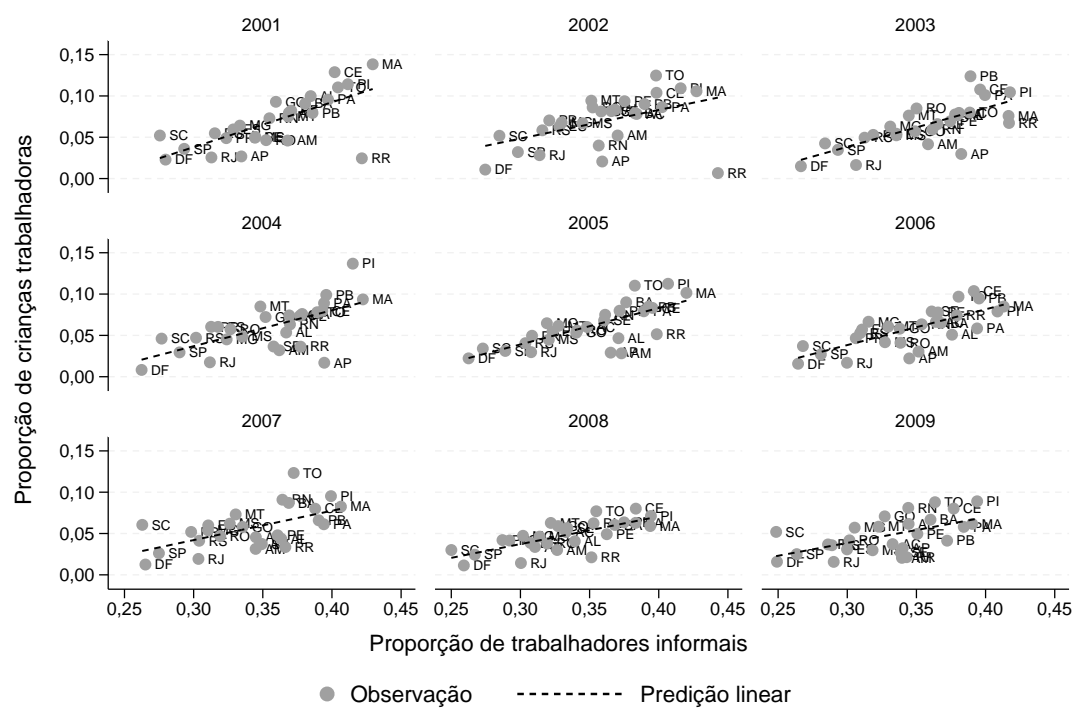

Fonte: Elaboração própria a partir dos dados da Pesquisa Nacional por Amostra de Domicílios (PNADs).

Figura 5: Brasil - Correlação entre a proporção de crianças trabalhadoras e a proporção de trabalhadores informais no mercado de trabalho por estados

Federal. Tais evidências são bastante sugestivas e consoantes com os fatores de demanda, uma vez que as crianças parecem ser mais atraídas ao trabalho ou facilmente absorvidas em regiões onde as atividades informais têm maior importância no emprego, dadas às relações precárias de trabalho que dificultam fiscalizações de órgãos reguladores.

Encerrando a exploração de correlações, a Figura 6 registra dados de dispersão entre a proporção de crianças trabalhadoras e a proporção de domicílios atendidos pelo Programa Bolsa Família nos estados brasileiros durante o período de 2004 a 2009. Os dados sugerem forte variabilidade e não permitem identificar um padrão de correlação linear que seja regular no tempo. Portanto, nesse estágio de investigação não há elementos suficientes para inferir qualquer associação entre a cobertura do Programa Bolsa Família e a taxa de trabalho infantil no Brasil.

A partir dos achados iniciais acima reportados, cabe explorar melhor os dados e sua dimensão temporal para controlar a influência de outras variáveis não observadas e entender melhor as relações de causalidade entre as variáveis estudadas anteriormente. Portanto, a seguir, são apresentados e discutidos os resultados empíricos acerca dos determinantes do trabalho infantil nos estados brasileiros.

\subsection{Determinantes do trabalho infantil: Evidências empíricas}

A Tabela 2, abaixo, apresenta os resultados de um conjunto de regressões feitas para a equação (6), com o objetivo de comparar diferentes especificações econométricas a partir dos estimadores de efeitos fixos (FE) e de efeitos aleatórios (RE). Inicialmente, são desconsiderados potenciais problemas de endo- 


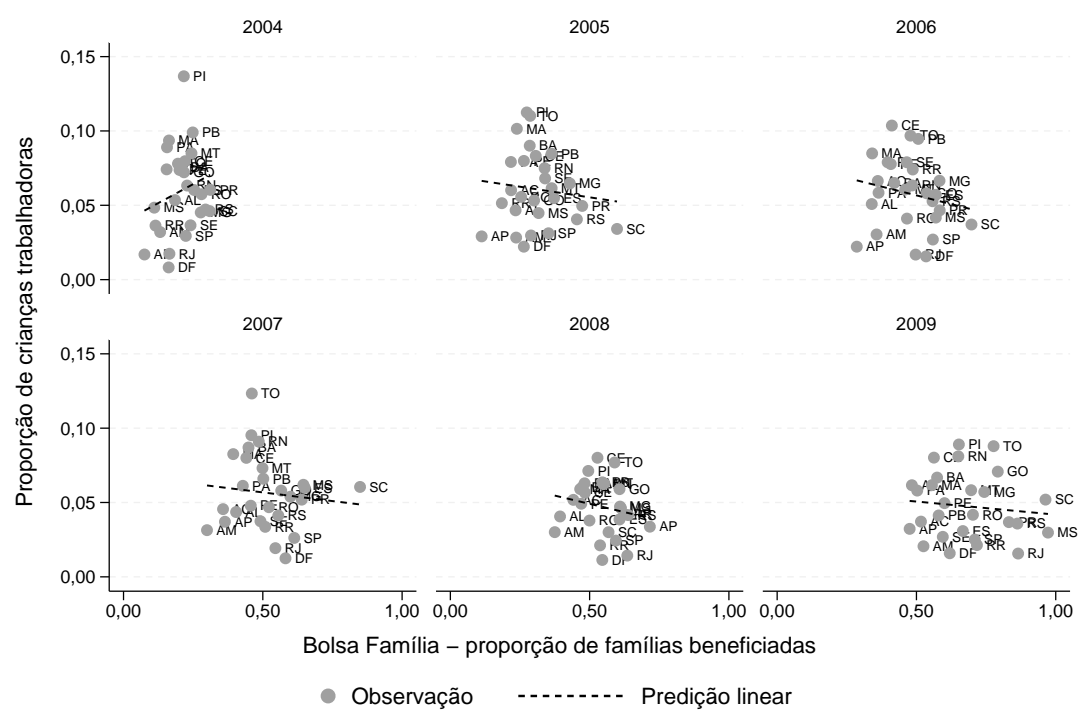

Fonte: Elaboração própria a partir dos dados da Pesquisa Nacional por Amostra de Domicílios (PNADs) e do IPEA.

Figura 6: Brasil - Correlação entre a proporção de crianças trabalhadoras e a proporção de famílias beneficiadas pelo programa Bolsa Família por estados

geneidade entre trabalho infantil e renda média estadual. Nas regressões com controle para efeitos fixos, a heterogeneidade não observada é considerada uma variável aleatória específica a cada unidade federativa e correlacionada com as covariadas observadas, enquanto nas regressões com efeitos aleatórios, os efeitos não observados de cada estado são supostos independentes daquelas covariadas (Cameron \& Trivedi 2005).

Apesar de serem observados com cautela, os resultados sugerem que a intensidade do trabalho infantil é menor nas unidades federativas com maior nível de renda, maior média de idade de ingresso das pessoas adultas no mercado de trabalho e com baixa importância dos empregos informais. Primeiro, note-se que, na maioria das regressões presentes na Tabela em destaque, há uma relação inversa e estatisticamente significativa entre a média de idade de ingresso no mercado de trabalho e a intensidade do trabalho infantil, assim como, entre a renda média estadual e a taxa de trabalho infantil. Segundo, a sucessiva introdução de covariadas aumentou o grau de ajuste dos modelos, de modo que as especificações das regressões presentes nas colunas (7) e (8) se revelaram bastante razoáveis. Todavia, o teste de especificação de Hausman sugere que, nas comparações entre estimadores alternativos, não se pode rejeitar a hipótese nula de que o estimador de efeitos aleatórios é mais apropriado ao comportamento dos dados.

Em particular, de acordo com os coeficientes estimados na regressão da coluna (8), um aumento de 1 ano na média de idade de entrada do adulto no mercado de trabalho reduz a taxa de trabalho infantil em cerca de 1,2 p.p. ${ }^{22}$

\footnotetext{
${ }^{22}$ O leitor pode consultar a Tabela B.2, no apêndice, e observar as estatísticas descritivas das variáveis empregadas nas regressões. Deve-se notar que as variáveis: proporção de crianças traba-
} 


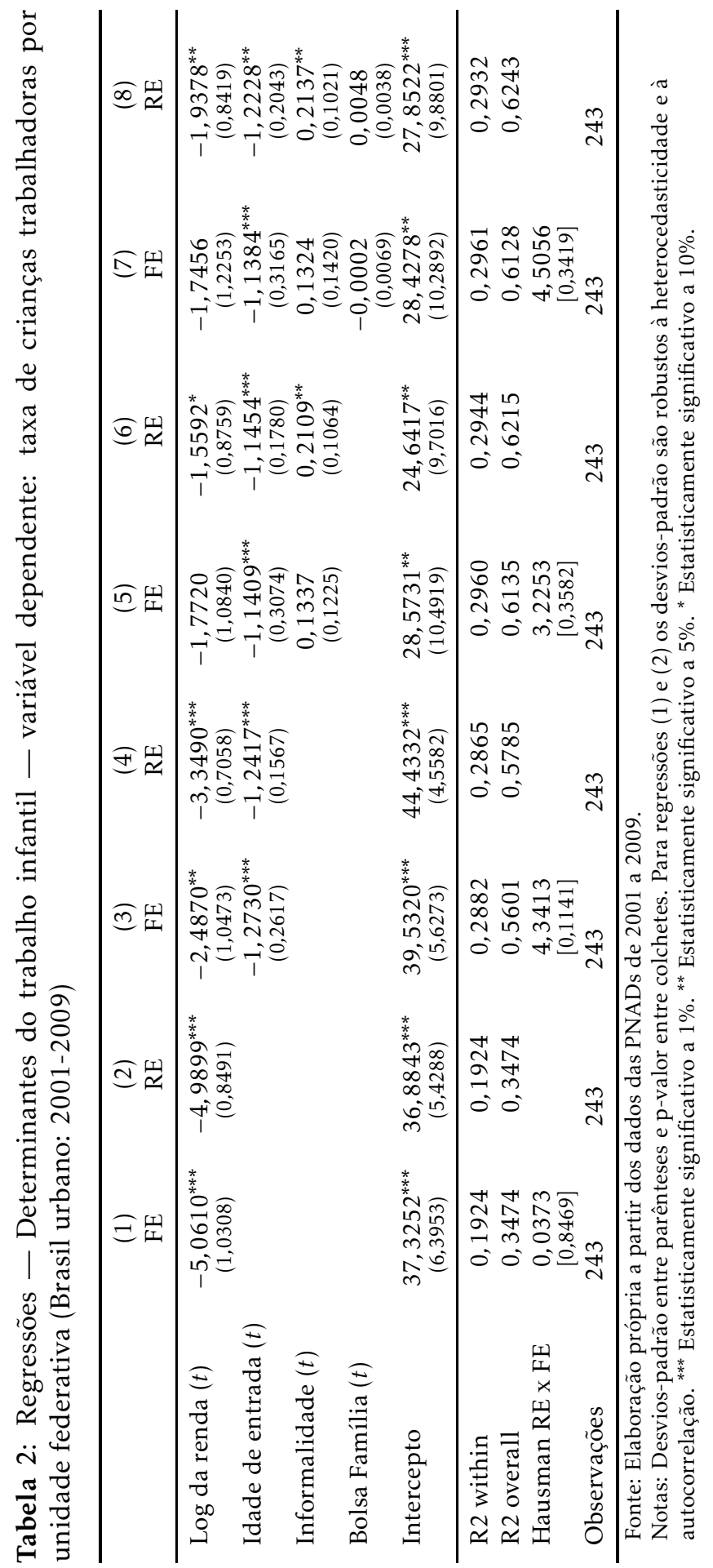


ao passo que uma elevação de 1 p.p. na renda média estadual diminui a intensidade de crianças trabalhadoras em 1,9 p.p. ${ }^{23}$ Ademais, uma elevação de 1 p.p. no grau de informalidade aumenta a taxa de trabalho infantil em 0,2 p.p. Esses resultados são consoantes com os estudos de Ilahi et al. (2000), Emerson \& Portela Souza (2002) e Pontili et al. (2008) para o Brasil, uma vez que esses últimos sugerem que a inserção precoce no mercado de trabalho tem efeitos negativos sobre a renda na idade adulta, e, portanto, pode aumentar a probabilidade de trabalho infantil da geração seguinte.

Na Tabela 3, a seguir, procura-se avançar na busca de evidências mais robustas ao considerar uma potencial endogeneidade entre a renda média e a taxa de trabalho infantil dos estados. Desse modo, são apresentados os resultados de regressões usando estimadores de efeitos fixos (FE-IV) e de efeitos aleatórios (RE-IV) com variáveis instrumentais. Enquanto nas regressões reportadas nas colunas (1) e (2), a renda e a escolaridade dos adultos, ambas defasadas em 1 período, foram empregadas como instrumentos para a renda média contemporânea, naquelas presentes nas colunas (3) e (4) foram usadas as mesmas variáveis com 1 e 2 anos de defasagem. A escolha desse conjunto de variáveis instrumentais foi baseada em evidências empíricas sobre a importância do capital humano na explicação das diferenças de renda (Cangussu et al. 2010), assim como, nos resultados do teste de Sargan-Hansen para sobreidentificação de restrições, cuja hipótese nula consiste na ausência de correlação entre os instrumentos empregados e os resíduos de cada modelo em destaque.

Conforme o teste de especificação de Hausman, as regressões com efeitos aleatórios se mostraram mais apropriadas que aquelas com efeitos fixos. Por outro lado, o teste de Sargan-Hansen sugere a não rejeição da ausência de correlação entre as variáveis instrumentais e os resíduos ao grau de significância $5 \%$. A referida hipótese nula pode não ser rejeitada com maior grau de confiança quando se consideram as regressões presentes nas colunas (3) e (4), as quais incluíram como instrumentos a renda média e escolaridade dos adultos defasadas em até 2 anos.

Nesse contexto, os resultados revelam que a renda média estadual e a idade de ingresso no mercado de trabalho afetam negativamente o trabalho infantil, enquanto a taxa de informalidade tem impacto positivo. Após controles para efeitos não observados específicos aos estados e para a possível endogeneidade entre renda e trabalho infantil, as regressões em análise também revelaram uma correlação direta entre taxa de famílias atendidas pelo Programa Bolsa Família e a taxa de trabalho infantil nos estados, embora os coeficientes estimados sejam, em geral, estatisticamente significativos a $10 \%$. Mais especificamente, os coeficientes estimados para a regressão presente na coluna (4) da Tabela 3 indicam que um incremento de 1 p.p. nas taxas de informalidade e de cobertura do Programa Bolsa Família, provocaria aumentos de 0,28 p.p. e 0,01 p.p., respectivamente, na taxa de trabalho infantil dos estados brasileiros. Já a elevação de 1 ano na média de idade de ingresso no mercado de trabalho reduz a intensidade do trabalho infantil de 1,14 p.p.

lhadoras, grau de informalidade e bolsa família foram regredidas como taxas (mesma unidade de medida) no intuito de simplificar a interpretação dos coeficientes estimados. Nesse caso, o efeito marginal deve ser interpretado em termos de variações em pontos percentuais.

${ }^{23}$ Nesse caso, o coeficiente estimado mensura o efeito de uma mudança relativa (pontos percentuais) na covariada sobre a variável dependente (especificação tipo Lin-Log). Em especial, como a variável dependente se acha em taxa, a resposta absoluta também deve ser interpretada em pontos percentuais. 
Tabela 3: Regressões com controle para endogeneidade - Determinantes do trabalho infantil - variável dependente: taxa de crianças trabalhadoras por unidade federativa (Brasil urbano: 2001-2009

\begin{tabular}{|c|c|c|c|c|}
\hline & $\begin{array}{l}(1) \\
\text { FE-IV }\end{array}$ & $\begin{array}{c}(2) \\
\text { RE-IV }\end{array}$ & $\begin{array}{l}(3) \\
\text { FE-IV }\end{array}$ & $\begin{array}{c}(4) \\
\text { RE-IV }\end{array}$ \\
\hline $\log$ da renda $(t)$ & $\begin{array}{c}-6,2669^{* *} \\
(3,0584)\end{array}$ & $\begin{array}{c}-2,8538^{* *} \\
(1,3875)\end{array}$ & $\begin{array}{c}-4,9695^{*} \\
(2,6395)\end{array}$ & $\begin{array}{r}-1,5812 \\
(1,3512)\end{array}$ \\
\hline Idade de entrada $(t)$ & $\begin{array}{c}-1,0521^{* * *} \\
(0,2942)\end{array}$ & $\begin{array}{c}-1,2907^{* * *} \\
(0,1811)\end{array}$ & $\begin{array}{c}-0,7548^{* *} \\
(0,3057)\end{array}$ & $\begin{array}{c}-1,1384^{* * *} \\
(0,1741)\end{array}$ \\
\hline Informalidade $(t)$ & $\begin{array}{c}0,1289 \\
(0,1089)\end{array}$ & $\begin{array}{r}0,1724^{*} \\
(0,0918)\end{array}$ & $\begin{array}{l}0,2738^{* *} \\
(0,1126)\end{array}$ & $\begin{array}{l}0,2806^{* * *} \\
(0,0910)\end{array}$ \\
\hline Bolsa Família $(t)$ & $\begin{array}{c}0,0190 \\
(0,0124)\end{array}$ & $\begin{array}{l}0,0094^{*} \\
(0,0053)\end{array}$ & $\begin{array}{l}0,0226^{*} \\
(0,0127)\end{array}$ & $\begin{array}{l}0,0112^{*} \\
(0,0060)\end{array}$ \\
\hline Intercepto & $\begin{array}{l}54,7261^{* * *} \\
(19,7645)\end{array}$ & $\begin{array}{l}35,7529^{* * *} \\
(11,8974)\end{array}$ & $\begin{array}{l}37,1664^{* *} \\
(17,1316)\end{array}$ & $\begin{array}{c}21,7968^{*} \\
(11,6222)\end{array}$ \\
\hline $\begin{array}{l}\text { Variáveis Instru- } \\
\text { mentais }\end{array}$ & & & & \\
\hline Log da renda $(t-1)$ & $\operatorname{sim}$ & $\operatorname{sim}$ & $\operatorname{sim}$ & $\operatorname{sim}$ \\
\hline Escolaridade $(t-1)$ & $\operatorname{sim}$ & $\operatorname{sim}$ & $\operatorname{sim}$ & $\operatorname{sim}$ \\
\hline Log da renda $(t-2)$ & não & não & $\operatorname{sim}$ & $\operatorname{sim}$ \\
\hline Escolaridade $(t-2)$ & não & não & $\operatorname{sim}$ & $\operatorname{sim}$ \\
\hline R2 within & 0,2325 & 0,2821 & 0,2616 & 0,2587 \\
\hline R2 overall & 0,5445 & 0,6245 & 0,5562 & 0,6529 \\
\hline Sargan-Hansen & $\begin{array}{l}0,7441 \\
{[0,3883]}\end{array}$ & $\begin{array}{l}3,5084 \\
{[0,0611]}\end{array}$ & $\begin{array}{l}2,3396 \\
{[0,5050]}\end{array}$ & $\begin{array}{l}6,0804 \\
{[0,1078]}\end{array}$ \\
\hline $\begin{array}{l}\text { Hausman RE-IV } x \\
\text { FE-IV }\end{array}$ & $\begin{array}{l}1,0571 \\
{[0,9010]}\end{array}$ & & $\begin{array}{l}6,8512 \\
{[0,1439]}\end{array}$ & \\
\hline Observações & 216 & 216 & 189 & 189 \\
\hline
\end{tabular}

No tocante aos resultados anteriores, primeiro, cabe ressaltar que o baixo grau de significância estatística e o reduzido impacto estimado para a cobertura do Bolsa Família, não permitem inferir com maior precisão a efetiva relação de causalidade desse Programa de transferência condicionada de renda com a intensidade do trabalho infantil nas unidades federativas. Segundo as evidências dos estudos de Schuwartzman (2001) e Cardoso \& Portela Souza (2004), programas de transferência de renda não apresentam efeitos significativos sobre a ocorrência de trabalho infantil no Brasil. Ainda assim, esses indícios permitem especular sobre como as condições econômicas presentes no meio urbano brasileiro poderiam incentivar os pais a manterem suas crianças no mercado de trabalho, apesar da transferência de renda derivada de programas sociais. Segundo, apesar da forte correlação inversa entre grau de informalidade e renda média estadual, ${ }^{24}$ após o controle para o viés de variáveis omitidas, os impactos dessas variáveis sobre o trabalho infantil se mostraram assimétricos e de acordo com a expectativa teórica.

A despeito do conjunto de evidências bastante sugestivas já reportadas, a análise dos determinantes do trabalho infantil a partir dos modelos dinâmicos de Arellano-Bond (GMM-AB) e Blundell-Bond (GMM-BB) pode fornecer

${ }^{24}$ Vide a Tabela B.1 no Apêndice. 
resultados mais críveis. Isso é possível já que os mesmos permitem testar o pressuposto de persistência temporal do trabalho infantil (ajustes friccionais no mercado de trabalho), assim como, geram ganhos de eficiência e o melhor uso de instrumentos (Wooldridge 2010). Nesse sentido, a Tabela 4 registra os resultados de um conjunto de seis regressões realizadas a partir de diferentes especificações para os referidos modelos dinâmicos. ${ }^{25}$

Os resultados fornecem uma série de evidências sugestivas e regulares em todas as regressões da Tabela em foco. Primeiro, parece haver uma persistência do trabalho infantil entre os estados brasileiros, isto é, aqueles estados com alta proporção de crianças trabalhadoras em anos precedentes tendem a manter a incidência desse fenômeno. Por exemplo, conforme os resultados da regressão presente na coluna (6), que inclui maior número de covariadas, o coeficiente de persistência temporal estimado para a taxa de trabalho infantil foi de cerca de 0,29 , isto é, pouco mais de $1 / 4$ do valor observado para a taxa de trabalho do período anterior tende a persistir no período seguinte. Tal evidência é consoante à hipótese de que os ajustes nos mercados de trabalho e/ou políticas de combate ao trabalho infantil apresentam efeitos defasados.

As diferenças estruturais dos mercados de trabalho no meio urbano dos estados também se revelaram importantes na explicação do trabalho infantil. Os resultados da Tabela 4 mostram que, quanto maior o grau de informalidade dos mercados, maior tende a ser o emprego de crianças. Nas regressões apresentadas nas colunas (5) e (6), por exemplo, os impactos estimados do grau de informalidade sobre a taxa de trabalho infantil foram, respectivamente, 0,29 p.p e 0,39 p.p. Esses achados são consoantes com o próprio caráter ilegal do trabalho infantil no Brasil e com a natureza precária dos empregos informais (trabalho sem carteira assinada, trabalho autônomo), que, por seu turno, facilita a inserção de crianças (Neves \& Menezes 2010).

Não menos importantes que os achados anteriores, são as evidências sobre a transmissão intergeracional do trabalho infantil. As estimativas em análise sugerem que naqueles estados onde os adultos começaram a trabalhar ainda bem jovens há maior presença de crianças no mercado de trabalho, isto é, um aumento de 1 ano na média de idade de ingresso do adulto no mercado de trabalho reduz em cerca de 1 p.p a intensidade de trabalho infantil. Dessa maneira, a referida persistência intergeracional sugere a atuação de uma armadilha de pobreza no Brasil, que tende a prolongar o trabalho infantil ao longo de gerações. Isso pode ocorrer em razão de o trabalho infantil dificultar a aquisição de capital humano, que é um importante determinante do nível de renda na fase adulta (Ilahi et al. 2000, Emerson \& Portela Souza 2002, Pontili et al. 2008, Lopes \& Pontili 2010).

Ainda observando os dados da Tabela 4, verifica-se que a renda média estadual e a cobertura do Bolsa Família não se mostraram estatisticamente significativas para explicar a taxa de trabalho infantil. Por outro lado, teste de Sargan-Hansen sugere não rejeitar a hipótese nula de exogeneidade das variáveis instrumentais a $10 \%$ de significância, sobretudo, nas regressões com estimador Arellano-Bond (GMM-AB), onde o grau de significância considerado

\footnotetext{
${ }^{25}$ As regressões baseadas nos estimadores GMM-AB incluíram os seguintes instrumentos: taxa de trabalho infantil e renda estadual defasadas a partir de $t-2$ e demais variáveis exógenas em primeira diferença. Já nos modelos GMM-BB, além dos instrumentos anteriores, foram incorporadas as primeiras diferenças defasadas da taxa de trabalho infantil e da renda estadual para equação em nível. Todas as variáveis defasadas foram derivadas a partir das condições de momentos do estimador GMM (vide Cameron \& Trivedi 2005).
} 


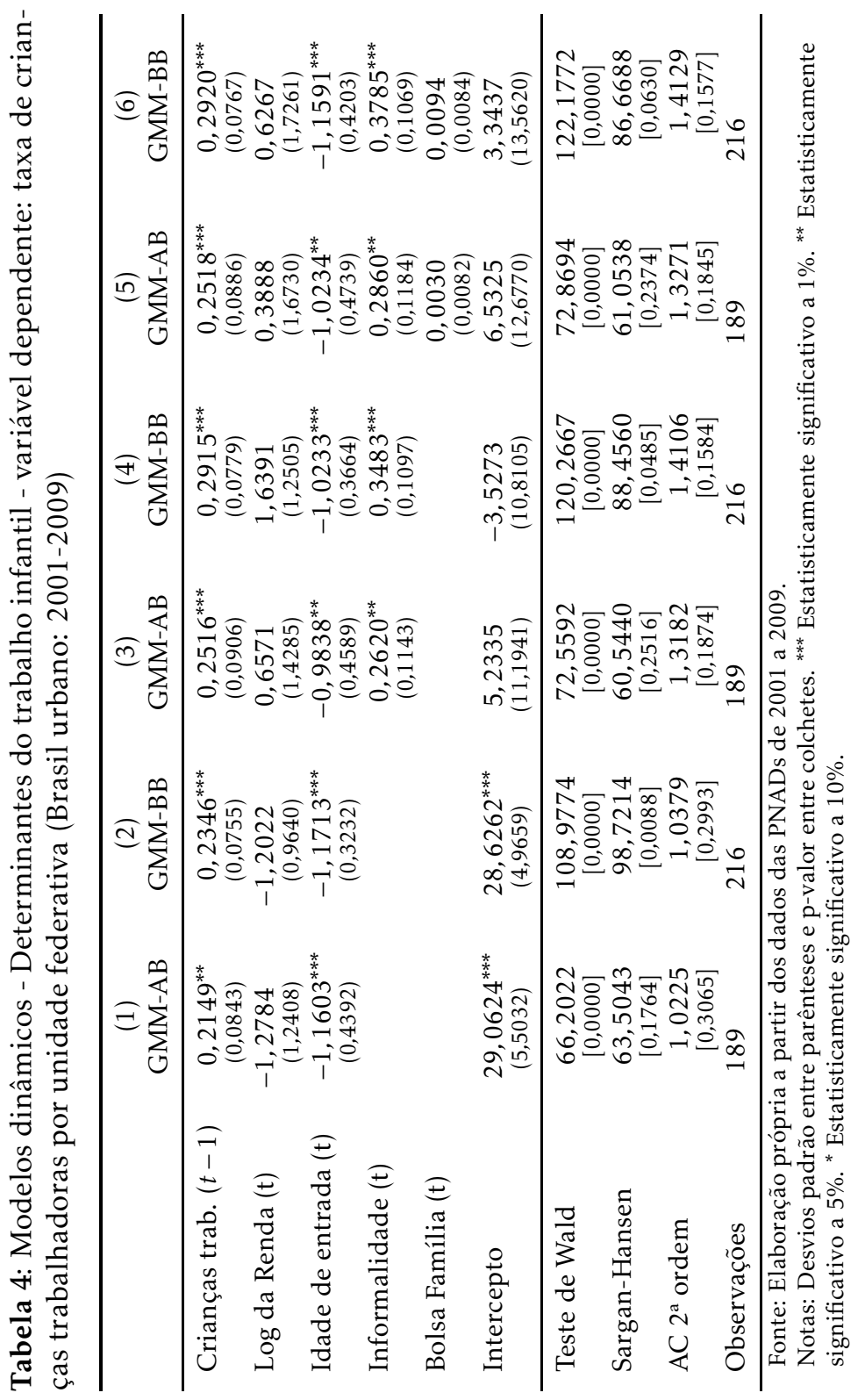


por ser de 5\%. Nas regressões obtidas com o estimador Blundell-Bond (GMM$\mathrm{BB}$ ) o teste de Sargan-Hansen se revelou mais sensível a diferentes especificações do modelo, corroborando a validade dos instrumentos a 5\% de significância apenas na regressão (5). ${ }^{26}$ Cabe ressaltar que a rejeição da hipótese nula do referido teste não necessariamente compromete a validade do modelo, visto que a fragilidade desse teste à especificação do modelo e ao número de instrumentos é bastante conhecida na literatura (Roodman 2009). Para contornar esse problema, Arellano \& Bond (1991) sugerem a aplicação do teste de autocorrelação de $2 \nmid$ ordem para os resíduos do modelo dinâmico. ${ }^{27}$ Dessa maneira, os resultados do último teste, em todas as regressões, sugerem não rejeitar a hipótese nula de ausência de correlação serial dos resíduos, o que, por seu turno, reforça a validade quanto à especificação dos modelos.

\section{Conclusão}

Os dados mais recentes das PNADs permitem identificar uma redução do trabalho infantil e uma tendência à universalização do acesso ao ensino fundamental durante as últimas décadas no Brasil. Contudo, no meio urbano esse processo parece ocorrer de forma mais moderada que na zona rural. Diante desse contexto, o presente artigo investigou os principais determinantes do trabalho infantil nos estados brasileiros, considerando as diferenças regionais de renda e de estrutura dos mercados de trabalho no meio urbano. Para tanto, foi utilizado um painel de dados construído a partir das PNADs divulgadas durante a década de 2000.

Os achados empíricos sugerem que o crescimento da renda parece induzir a redução da participação de crianças no mercado de trabalho, embora esse efeito não se mantenha quando se considera a persistência do trabalho infantil no tempo. Por outro lado, aqueles estados com maior importância de empregos informais absorveram mais crianças no mercado de trabalho; resultado que apresentou regularidade em várias regressões com controles para efeitos de variáveis omitidas e endogeneidade entre renda estadual e trabalho infantil.

Outro conjunto importante de evidências diz respeito às persistências intergeracional e temporal do trabalho infantil. No primeiro caso, os resultados encontrados sugerem que nos estados onde os adultos ingressaram precocemente no mercado de trabalho, maior deve ser a taxa de crianças trabalhadoras. Por outro lado, também é bem documentada na literatura nacional a existência de uma relação inversa entre idade de entrada no mercado de trabalho e salário atual do trabalhador (Ilahi et al. 2000, Emerson \& Portela Souza 2002, Pontili et al. 2008). Portanto, os achados do presente estudo reforçam a hipótese de uma "armadilha de pobreza" no Brasil, isto é, adultos que investem pouco em educação tendem a direcionar precocemente seus filhos à atividade laboral. Já no tocante à persistência temporal, os resultados dos modelos dinâmicos indicam que aqueles estados com alta taxa de trabalho infantil em anos precedentes preservam cerca de $1 / 4$ dessa incidência nos anos seguintes;

\footnotetext{
${ }^{26}$ Embora não apresentadas, vale ressaltar que outras especificações foram testadas, incluindo defasagens de até dois períodos para as variáveis: trabalho infantil, renda domiciliar per capita e escolaridade. No entanto, os resultados não se mostraram satisfatórios em termos de significância dos parâmetros e dos testes de Sargan.

${ }^{27}$ Vide Arellano \& Bond (1991) para maiores detalhes.
} 
dado que sugere possíveis efeitos defasados na aplicação de políticas públicas de combate ao referido fenômeno.

Os resultados empíricos não se revelaram conclusivos no tocante ao impacto do Programa Bolsa Família sobre o trabalho infantil no meio urbano brasileiro. Em poucas regressões foi observada uma correlação positiva entre a taxa de cobertura do referido Programa e a taxa de trabalho infantil dos estados; achados que não sobreviveram nos modelos dinâmicos. Portanto, pesquisas futuras devem explorar com maior profundidade em que medida os incentivos econômicos ao trabalho infantil no meio urbano podem compensar o aumento de renda derivado das transferências governamentais.

De uma forma geral, os resultados desse estudo sugerem que as políticas de combate ao trabalho infantil não devem se restringir apenas às transferências condicionadas de renda, mas permitir investimentos importantes na qualidade e no acesso à educação, assim como, maiores estímulos à geração de oportunidades e formalização das atividades econômicas.

\section{Referências Bibliográficas}

Aquino, J. M., Fernandes, M. M., Pazello, E. T. \& Scorzafave, L. G. (2010), 'Trabalho infanfil: Persistência intergeracional e decomposição da incidência entre 1992 e 2004 no Brasil rural e urbano', Revista de Economia Contemporânea 14(1), 61-84.

Arellano, M. \& Bond, S. (1991), 'Some tests of specification for panel data: Monte carlo evidence and an application to employment equations', Review of Economic Studies 58(2), 277-297.

Baltagi, B. H. (2008), Econometric analysis of panel data, 4 edn, IE-Wiley.

Banerjee, A. V. \& Newman, A. F. (1993), 'Occupational choice and the process of development', Journal of Political Economy 101(2), 274-298.

Barham, V., Boadway, R., Marchand, M. \& Pestueau, P. (1995), 'Education and the poverty trap', European Economic Review 39(7), 1257-1275.

Basu, K. (2000), 'The intriguing relationship between adult minimum wage and child labor', Economic Journal 110(46), 50-61.

Basu, K. \& Tzannatos, Z. (2003), 'The global child labor problem: what do we know and what can we do?', World Bank Economic Review 17(2), 147-173.

Basu, K. \& Van, P. H. (1998), 'The economics of child labor', American Economic Review 88(3), 412-427.

Bhalotra, S. \& Heady, C. (2003), 'Child farm labor: the weath paradox', The World Bank Economic Review 17(2), 197-227.

Blundell, R. \& Bond, S. (1998), 'Initial conditions and moment restrictions in dynamic panel data models', Journal of Econometrics 87(1), 115-143.

Brasil (1998), 'Trabalho infantil no brasil: questões e políticas', Presidência da República. Secretaria de Comunicação Social. Brasília. 
Cacciamali, M. C., Tatei, F. \& Ferreira Batista, N. (2010), 'Impactos do programa bolsa família federal sobre o trabalho infantil e a frequência escolar', Revista Economia Contemporânea 14(2), 269-301.

Cameron, A. C. \& Trivedi, P. K. (2005), Microeconometrics: methods and applications, New York: Cambridge University Press.

Cangussu, R. C., Salvato, M. A. \& Nakabashi, L. (2010), 'Uma análise do capital humano sobre o nível de renda dos estados brasileiros: Mrw versus mincer', Estudos Econômicos 40(1), 153-183.

Cardoso, E. \& Portela Souza, A. (2004), 'The impact of cash transfers on child labor and school attendance in Brazil', Working Papers. Nashville: Vanderbilt University (407).

Duarte, G. B. \& Silveira Neto, R. M. (2008), 'Avaliando o impacto do programa bolsa família sobre a frequência escolar: o caso da agricultura familiar no Nordeste do Brasil', In: Encontro Nacional da ANPEC, 36., Bahia. Anais...

Duryea, S. \& Arends-Kuenning, M. (2003), 'School attendance, child labor and local labor market fluctuations in urban Brazil', World Development 31(7).

Edmonds, E. V. \& Schady, N. (2012), 'Poverty alleviation and child labor', American Economic Journal: Economic Policy, American Economic Association $4(4), 100-124$.

Emerson, P. M. \& Portela Souza, A. F. (2002), 'From childhood to adulthood: the effects of child labor activities on adult earnings in Brazil', In: Latin American Economics Association - LACEA, Madrid. Anais...

Fernandes, R. \& Portela Souza, A. F. (2003), 'A redução do trabalho infantil e o aumento da frequência à escola: uma análise de decomposição para o Brasil dos anos 90', Disponível em: $<$ http://www.econ.fea.usp.br/seminarios/artigos/portela.pdf >. Acesso em: 20. set. 2010.

Ferreira Batista, N. (2006), 'Trabalho infantil e migração no estado de São Paulo', Tese (Doutorado) - Instituto de Pesquisas Econômicas da Faculdade de Economia, Administração e Contabilidade - Universidade de São Paulo .

Ferreira Batista, N. N. \& Cacciamali, M. C. (2007), 'Migração familiar, trabalho infantil e ciclo intergeracional da pobreza no estado de São Paulo', In: Encontro Regional da ABET, 6., Paraíba. Anais... João Pessoa: ABET.

Glewwe, P. \& Kassouf, A. L. (2008), 'The impact of the Bolsa Escola/Família conditional cash transfer program on enrollment, grade promotion and drop out rates in Brazil', In: Encontro Nacional da ANPEC, 36., Bahia. Anais...Salvador.

Grootaert, C. \& Kandur, R. (1995), 'Child labor: an economic perspective', International Labour Review 132(2), 187-203.

Gunnarsson, V., Orazem, P. F. \& Sanchez, M. A. (2006), 'Child labor and school achievement in Latin America', The Word Bank Economic Review 20(1), 31-54. 
Ilahi, N. P., Orazem, P. F. \& Sedlacek, G. (2000), 'The implications of child labor for adult wages, income and poverty: retrospective evidence from Brazil', In: V Meeting of the Network on Inequality and Poverty (NIP), Madrid.

Jafarey, S. \& Lahiri, S. (2005), Education, child labour and development, in G. Johnes \& J. Johnes, eds, 'Handbook of development economics', Elsevier Science, pp. 743-786.

Kassouf, A. L. (2002), 'Aspectos sócio-econômicos do trabalho infantil no Brasil', In: Encontro da ABEP,13., Minas Gerais. Anais...Belo Horizonte.

Kassouf, A. L. (2006), 'Trabalho infantil: causas e consequências', In:Estudo realizado para apresentação no concurso de Professor Titular - Departamento de Economia, Administração e Sociologia da ESALQ, USP, São Paulo.

Kassouf, A. L. (2007), 'O que conhecemos sobre o trabalho infantil?', Revista Nova Economia 17(2), 323-350.

Lopes, J. L. \& Pontili, R. M. (2010), 'Inserção precoce no mercado de trabalho e baixo nível de escolaridade como condicionante do nível de renda no futuro: análise e aplicações de um modelo probit para o Nordeste brasileiro', In:Encontro Regional de Economia - ANPEC, Anais... Fortaleza.

MTE (2001), 'Política e ações para o combate ao trabalho infantil no Brasil', Ministério do Trabalho e Emprego. Brasília.

Neves, E. C. \& Menezes, T. A. (2010), 'Bolsa Família, crises econômicas e trabalho infantil: diferentes impactos no Nordeste e Sudeste', In:Encontro Nacional da ENABER, 13., Minas Gerais. Anais... Belo Horizonte.

OIT (2001), Combatendo o trabalho infantil: guia para educadores, Brasília: IPEC.

Pontili, R. M., Lopes, J. L. \& Souza, E. L. C. (2008), 'Trabalho infantil e sua influência sobre a renda e a escolaridade da população trabalhadora do Paraná', In:Seminário do Trabalho, 6., Trabalho, Economia e Educação no século XXI, São Paulo. Anais... Marília.

Ray, R. (2002), 'The determinants of child labour and child schooling in Ghana', Journal of African Economies 11(4), 561-590.

Roodman, D. (2009), 'How to do xtabond2: An introduction to difference and system GMM in Stata', The Stata Journa 9(1), 86-136.

Santos, C. F. \& Portela Souza, A. F. (2007), 'A redução do trabalho infantil e o aumento da frequência escolar na década de 90 no Brasil', In:Encontro Nacional da ANPEC. Anais... Recife: ANPEC.

Schuwartzman, S. (2001), Trabalho infantil no Brasil, Brasília: OIT.

Schwartzman, S. \& Schwartzman, F. F. (2004), 'O trabalho infantil no Brasil', Instituto de Estudos do Trabalho e Sociedade/UFRJ 2.

Silveira, C., Amaral, C. \& Campineiro, D. (2000), Trabalho infantil: examinando o problema, avaliando estratégias de erradicação, NAPP/UNICEF.

Wooldridge, J. M. (2010), Econometric analysis of cross section and panel data, 2 edn, Ed, MIT Press. 


\section{Apêndice A Teste de Hausman}

O teste de especificação desenvolvido por Hausman, em 1978, é bastante utilizado para a escolha entre os estimadores de efeitos fixos e de efeitos aleatórios (Wooldridge 2010). A estatística é dada por:

$$
H=\left(\hat{\beta}_{F E}-\hat{\beta}_{R E}\right)^{\prime}\left[\operatorname{var}\left(\hat{\beta}_{F E}\right)-\operatorname{var}\left(\hat{\beta}_{R E}\right)\right]^{-1}\left(\hat{\beta}_{F E}-\hat{\beta}_{R E}\right)
$$

onde: $\hat{\beta}_{R E}$ representa o vetor estimado por efeitos aleatórios sem os coeficientes das variáveis constantes no tempo; $\hat{\beta}_{F E}$ o vetor de parâmetros correspondente ao estimador de efeitos fixos e var(.) a matriz de covariância dos referidos estimadores. A referida estatística segue uma distribuição QuiQuadrado com grau de liberdade igual a posto da matriz diferença de covariância $\left[\operatorname{var}\left(\hat{\beta}_{F E}\right)-\operatorname{var}\left(\hat{\beta}_{R E}\right)\right]$, supostamente definida positiva.

A hipótese nula do teste de Hausman é de ausência de diferenças sistemáticas entre os parâmetros estimados por efeitos fixos e por efeitos aleatórios, isto é, os coeficientes do modelo de efeitos aleatórios são ortogonais aos resíduos. A rejeição da hipótese nula indica que o modelo adequado é o de efeitos fixos.

\section{Apêndice B Teste de Sargan-Hansen}

O teste de Sargan-Hansen ou teste de sobreidentificação de restrições é utilizado para verificar a validade de instrumentos adicionais, uma vez que, em modelos exatamente identificados, as condições de momentos não permitem testar a exogeneidade de variáveis instrumentais (Roodman 2009). A estatística do teste é dada por:

$$
S=\hat{\varepsilon}^{\prime} Z_{i}\left[\frac{1}{N} \sum_{i=1}^{N} Z_{i}^{\prime} \hat{\varepsilon} \hat{\varepsilon}^{\prime} Z_{i}\right]^{-1} Z_{i}^{\prime} \hat{\varepsilon}
$$

onde: $N$ é o total de observações agrupadas no painel de dados; $Z_{i}$ é a matriz de variáveis instrumentais para o estado $i$ e $\hat{\varepsilon}$ um vetor de resíduos em primeira diferença estimado para cada estado $i$.

A hipótese nula deste teste afirma que os instrumentos são válidos, isto é, eles não são correlacionados com os erros na equação em primeira diferença. Sob essa hipótese, a estatística de teste segue uma distribuição Qui-Quadrado com grau de liberdade igual ao total de instrumentos menos o número de parâmetros do modelo. 


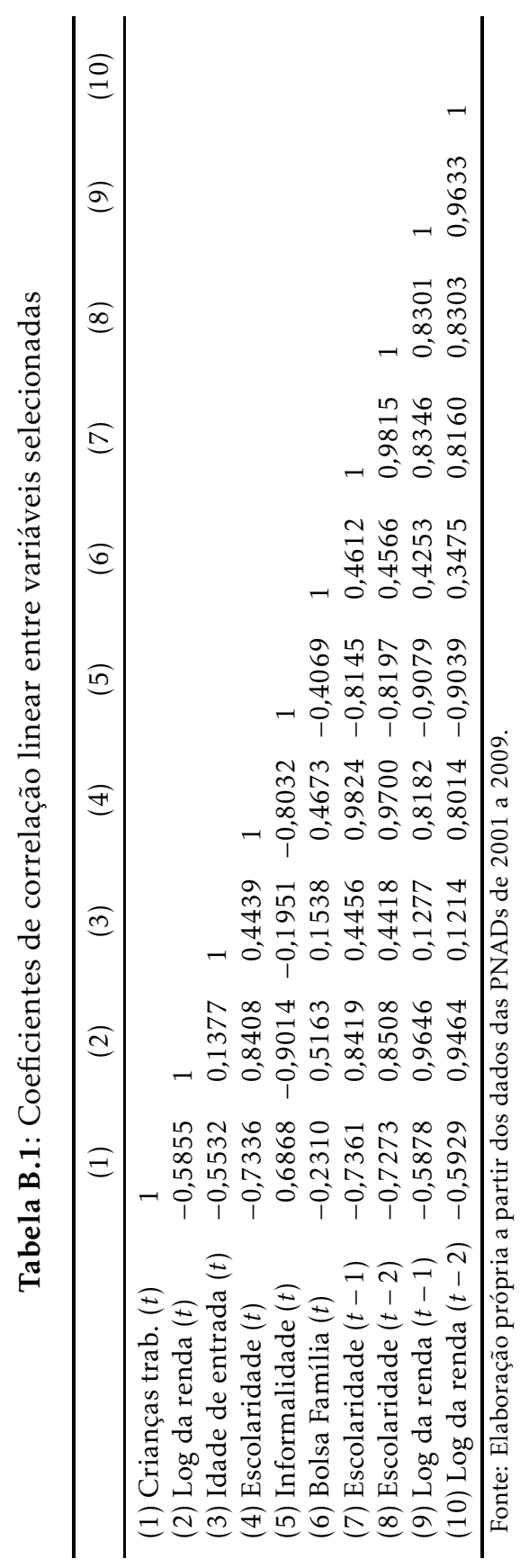


Tabela B.2: Estatísticas descritivas da amostra

\begin{tabular}{lrcrrc}
\hline Variável & Média & Desvio-padrão & Mínimo & Máximo & Observações \\
\hline Crianças trabalhadoras $(t)$ & 5,93 & 2,69 & 0,66 & 13,83 & 243 \\
Log da renda $(t)$ & 6,20 & 0,33 & 5,56 & 7,20 & 243 \\
Idade de entrada $(t)$ & 14,28 & 0,94 & 11,87 & 16,65 & 243 \\
Escolaridade $(t)$ & 6,78 & 0,93 & 4,82 & 9,73 & 243 \\
Informalidade $(t)$ & 34,67 & 4,21 & 24,86 & 44,27 & 243 \\
Bolsa Família $(t)$ & 30,15 & 26,10 & 0,00 & 97,22 & 243 \\
Escolaridade $(t-1)$ & 6,70 & 0,91 & 4,82 & 9,49 & 216 \\
Escolaridade $(t-2)$ & 6,61 & 0,89 & 4,82 & 9,42 & 189 \\
Log da renda $(t-1)$ & 6,18 & 0,33 & 5,56 & 7,16 & 216 \\
Log da renda $(t-2)$ & 6,16 & 0,32 & 5,56 & 7,15 & 189 \\
\hline
\end{tabular}

Fonte: Elaboração própria a partir dos dados das PNADs de 2001 a 2009. 